\title{
Rapid and accurate estimates of streamflow depletion caused by groundwater pumping using analytical depletion functions
}

3 Samuel C. Zipper'1, Tom Gleeson ${ }^{1}$, Ben Kerr², Jeanette K. Howard ${ }^{3}$, Melissa M. Rohde ${ }^{4}$, 4 Jennifer Carah $^{3}$, Julie Zimmerman

$5 \quad{ }^{1}$ Department of Civil Engineering, University of Victoria, Victoria BC, Canada

$6 \quad{ }^{2}$ Foundry Spatial Ltd, Victoria BC, Canada

$7 \quad{ }^{3}$ The Nature Conservancy, 201 Mission Street, $4{ }^{\text {th }}$ Floor, San Francisco, CA, 94105, USA

$8{ }^{4}$ The Nature Conservancy, 877 Cedar Street, Suite 242, Santa Cruz, CA, 95060, USA

$9{ }^{5}$ The Nature Conservancy, 555 Capitol Mall, Suite 1290, Sacramento, CA, 95814, USA

10 Corresponding author: Samuel C. Zipper (samzipper@ku.edu)

11 Key Points $(\leq \mathbf{1 4 0}$ characters each):

- Analytical depletion functions (ADFs) are tools to estimate streamflow depletion caused by groundwater pumping within real stream networks

- ADFs use stream proximity criteria, depletion apportionment equations, and analytical models to provide distributed estimate of depletion

- ADFs are able to identify most-affected stream for $\geq 70 \%$ of pumping wells with mean absolute error $\leq 15 \%$ of predicted range of depletion 


\section{Abstract}

22 Reductions in streamflow due to groundwater pumping ('streamflow depletion') can negatively

23 impact water users and aquatic ecosystems but are challenging to estimate due to the time and expertise required to develop numerical models often used for water management. Here, we develop analytical depletion functions, which are simpler approaches consisting of (i) stream proximity criteria which determine the stream segments impacted by a well; (ii) a depletion apportionment equation which distributes depletion among impacted stream segments; and (iii) an analytical model to estimate streamflow depletion in each segment. We evaluate 50 analytical depletion functions via comparison to an archetypal numerical model and find that analytical depletion functions predict streamflow depletion more accurately than analytical models alone. The choice of a depletion apportionment equation has the largest impact on analytical depletion function performance, and equations that consider stream network geometry perform best. The best-performing analytical depletion function combines stream proximity criteria which expand through time to account for the increasing size of the capture zone, a web squared depletion apportionment equation which considers stream geometry, and the Hunt analytical model which includes streambed resistance to flow. This analytical depletion function correctly identifies the stream segment most affected by a well $\geq 70 \%$ of the time with mean absolute error $<15 \%$ of predicted depletion and performs best for wells in relatively flat settings within $\sim 3 \mathrm{~km}$ of streams. Our results indicate that analytical depletion functions may be useful water management decision support tools in locations where calibrated numerical models are not available.

\section{Plain Language Summary}

42 Groundwater pumping can reduce streamflow ('streamflow depletion'), but it is hard to determine which streams will be affected by a well and how much each stream will be depleted. In this study, we develop and test simple tools called analytical depletion functions that can be used to estimate streamflow depletion in real-world settings where more complex models or field estimates are not available. We find that analytical depletion functions accurately predict which stream will be most affected by groundwater pumping for $\geq 70 \%$ of wells and accurately estimate the amount of depletion. Thus, we conclude that analytical depletion functions are a useful tool to provide rapid, screening-level estimates of streamflow depletion for water managers in areas where more complex approaches are unavailable. By integrating analytical depletion functions into online decision support tools, it will be possible for non-experts to quickly estimate reductions in streamflow caused by groundwater pumping from existing and/or proposed wells.

54 


\section{Introduction}

Effective conjunctive management of surface water and groundwater requires information about the impacts of groundwater pumping on streamflow, which is often poorly known. Groundwater pumping reduces streamflow ('streamflow depletion') by capturing groundwater which would have otherwise discharged into streams or inducing infiltration from the stream into the aquifer (Barlow et al., 2018; Bredehoeft et al., 1982). This can have negative consequences on surface water users and aquatic ecosystems, both of which depend on a stable contribution of groundwater to streamflow (Gleeson \& Richter, 2017; Larsen \& WoelfleErskine, 2018; Perkin et al., 2017; Rohde et al., 2017, 2018). However, quantifying streamflow depletion is challenging due to the complexity of modeling groundwater-surface water interactions (Barlow \& Leake, 2012). To guide sustainable water management, it is critical to develop approaches to estimate streamflow depletion that can allow local water managers to make informed decisions on groundwater withdrawals in a variety of settings (White et al., 2016).

Streamflow depletion can be modeled using numerical or analytical models (Table S1; Zipper et al., 2018a). Numerical models (e.g. MODFLOW) are process-based representations of the physics governing groundwater flow and are therefore ideal for local water management applications such as estimating streamflow depletion. However, the time, expertise, and financial costs associated with their development make them impractical for most areas around the world. Analytical models offer water managers a simpler approach to estimate streamflow depletion, but do not simulate most of the processes and real-world complexity included in numerical models. Due to the relative ease of implementing analytical models, they have been suggested as a path towards developing real-time, web-based conjunctive management decision support tools in locations where numerical models do not exist (Huggins et al., 2018). The only functional example the authors are aware of is the Michigan Water Withdrawal Assessment Tool (http://www.deq.state.mi.us/wwat), which integrates a streamflow depletion model with a fish ecological model and is a required step to approve proposals that permit new or increased large quantity withdrawal from the surface or groundwater (Hamilton \& Seelbach, 2011; Reeves et al., 2009, 2010; Zorn et al., 2012).

Given their practicality, numerous analytical models have been developed to calculate streamflow depletion for different hydrogeological conditions (reviewed in Huang et al., 2018 and Hunt, 2014). Most analytical models assume either one or two linear streams with aquifers extending infinitely away from the stream, though some analytical models have been developed for more complex settings. For instance, Yeh et al. (2008) provide an analytical model for a well between two intersecting streams, and Singh (2009) for a well next to a stream with a right-angle bend. Despite these advances, there are still many real-world settings in which even the most complex analytical models cannot predict streamflow depletion, such as domains with $>2$ streams or sinuous stream networks (Barlow \& Leake, 2012).

In these complex real-world settings, recent work has suggested integrating analytical models with depletion apportionment equations, which are geometric methods used to distribute the impacts of pumping among stream segments within the surrounding stream network (Reeves et al., 2009; Zipper et al., 2018a). To use depletion apportionment equations, we suggest it is first necessary to identify the subset of streams within the domain which may be impacted by a well using stream proximity criteria. Here, we introduce the term analytical depletion function to refer 
to the combination of an analytical model with a depletion apportionment equation calculated for streams meeting a given set of stream proximity criteria.

For use in water management decision-making, it is necessary to rigorously evaluate the performance of analytical depletion functions. However, many aspects of analytical depletion functions remain untested, particularly their performance under transient conditions. During the development of the Michigan Tool, Reeves et al. (2009) found that the best match to numerical model results was the Hunt (1999) analytical model with an inverse distance-based depletion apportionment equation using adjacent catchments as the stream proximity criteria. However, this comparison was only conducted for a single timestep (after 5 years of pumping) and a single stream in Michigan. Subsequently, Zipper et al. (2018a) tested 5 depletion apportionment equations across a range of stream network geometries in British Columbia and found that depletion apportionment equations which considers stream network geometry best matched numerical model results across several stream network and aquifer configurations. However, this comparison was under steady-state conditions and therefore did not investigate different stream proximity criteria, analytical models, or performance through time.

Here, we conduct a systematic evaluation of the performance of analytical depletion functions and each of the components (analytical model, depletion apportionment equation, and stream proximity criteria) under transient conditions in order to advance the utility of analytical depletion functions as a potential decision support tool. Specifically, we investigate the questions:

(1) How does the choice of analytical model, depletion apportionment equation, and stream proximity criteria affect the performance of analytical depletion functions?

(2) How does the performance of analytical depletion functions change through time under transient conditions?

(3) What are the primary landscape attributes associated with errors in analytical depletion functions?

\section{Formulation of analytical depletion functions}

We define an analytical depletion function as the combination of three components shown in Figure 1: stream proximity criteria (Section 2.1), a depletion apportionment equation (Section 2.2), and an analytical streamflow depletion model (Section 2.3). First, the stream proximity criteria are used to identify all stream segments that may be affected by a given well (Figure 1, Step 1). Second, the depletion apportionment equation is used to estimate the fraction of total depletion $\left(f_{i}\right)$ which is apportioned to each stream segment, $i$, meeting the stream proximity criteria (Figure 1, Step 2). Third, the analytical model is used to estimate the volumetric streamflow depletion rate ignoring other stream segments $\left(Q a_{i}\right)$ for each stream segment meeting the stream proximity criteria (Figure 1, Step 3). Finally, for each stream segment the estimated depletion $\left(Q d_{i}\right)$ as a fraction of the pumping rate $(Q w)$ is calculated as the product of the fraction of total depletion estimated using the depletion apportionment equations and the streamflow depletion rate estimated using the analytical model (Figure 1, Step 4; Equation 1):

$$
Q d_{i}=f_{i}\left(\frac{Q a_{i}}{Q w}\right)
$$


$Q d, i$ is known as depletion potential (Barlow et al., 2018; Fienen et al., 2018) and is between 0\% (stream-aquifer flux is unaffected by pumping) and $100 \%$ (the change in stream-aquifer flux is equal to the pumping rate). Table 1 summarizes symbols and abbreviations used throughout the manuscript. Analytical depletion functions are available as part of the streamDepletr package for R (Zipper, 2019).

\subsection{Stream proximity criteria}

Stream proximity criteria define the stream segments which could potentially be depleted by a given well, and to our knowledge have never been explicitly defined or tested in previous

The whole domain stream proximity criteria are the most permissive and use all stream segments within the domain (Figure 2a), which is described in Section 3.

The local area stream proximity criteria retain any stream segment within a specified distance of the well ( $r$ in Figure 1, Step 1). This is based on the 'local area' concept for a well, which is the area in which the effects of pumping are likely to impact streams (Feinstein et al., 2016; Fienen et al., 2016). We define our local area by calculating double the maximum distance from any land point to the closest stream segment within our domain (Section 3.2), which ensures that $\geq 1$ stream segments are potentially affected by each well.

The adjacent stream proximity criteria, proposed by Reeves et al. (2009), retain all stream segments in the catchment containing the well and neighboring catchments. To identify which stream segments are adjacent to the well, we use the stream segments with non-zero depletion fractions estimated by the Thiessen Polygon depletion apportionment equation (see Section 2.2).

The expanding stream proximity criteria, introduced in this study, uses the analytical model (Section 2.3) to determine the maximum distance from a well with a depletion potential of at least $1 \%$ for the timestep of interest and retains all stream segments within this distance of the well ( $r$ in Figure 1, Step 1). Unlike the whole domain, local area, and adjacent criteria (which are static through time), the expanding criteria retain more stream segments at later timesteps. We also evaluated the sensitivity of these criteria to the 1\% threshold (Section 3.6).

The adjacent + expanding stream proximity criteria combine the adjacent and expanding criteria by considering any stream segment that is either in the catchment containing or neighboring the well (adjacent), or within the maximum distance with a depletion potential $\geq 1 \%$ at a given timestep (expanding). Thus, when the expanding radius is very small (e.g. shortly after the start of pumping), the results are identical to the adjacent method, and when the expanding radius is very large the results are identical to the expanding method.

\subsection{Depletion apportionment equations}

We evaluated the same five depletion apportionment equations as Zipper et al. (2018a). We briefly described them here (Figure 1, Step 2):

The Thiessen polygon (Equation 2) is an area-based, rather than distance-based, depletion apportionment equation. It uses two overlapping sets of Thiessen polygons. The first set of polygons is created using the points on each stream segment closest to the well, so there is one polygon corresponding to each stream segment. The second set of polygons is created using the 
point location of the well in addition to the points on each stream segment closest to the well. For each stream segment, $f_{i}$ is calculated as:

$$
f_{i}=\frac{a_{i}}{a_{w}}
$$

where $a_{i}$ is the area of the polygon for stream segment $i$ from the first set which overlaps with the polygon from the second set containing the well, and $a_{w}$ is the area of the polygon from the second set which contains the well (Figure 1, Step 2). Because this is an area-based method, the depletion apportionment results from this method are the same for all stream proximity criteria.

The inverse distance and inverse distance squared depletion apportionment equations (Equation 3) weight depletion across different segments based on the inverse of the distance between the well and each stream segment:

$$
f_{i}=\frac{\frac{1}{d_{i}^{W}}}{\sum_{j=1, n} \frac{1}{d_{j}^{W}}}
$$

where $d$ is the horizontal distance to the closest point on each stream segment from the well as in Figure 1 Step 2, $n$ is the number of stream segments meeting the stream proximity criteria, and $w$ is a weighting factor used to define inverse distance $(w=1)$ or inverse distance squared $(w=2)$.

The web and web squared depletion apportionment equations (Equation 4) are similar to the inverse distance and inverse distance squared approaches, but instead of using only the point on each stream segment closest to the well they divide each stream segment into a series of equally spaced $(5 \mathrm{~m})$ points and then weight depletion based on all of these points (Figure 1, Step 2). By dividing each stream segment into a series of points, the web and web squared methods apportion depletion based on the length of each stream segment which is consistent with analytical model theory developed for streams of finite length (Kollet et al., 2002). For each stream segment, $i$, the fraction of total depletion apportioned to that segment, $f_{i}$, is calculated as:

$$
f_{i}=\frac{\sum_{p=1, P_{i}} \frac{1}{d_{i, p}^{W}}}{\sum_{j=1, n}\left(\sum_{p=1, P_{j}} \frac{1}{d_{j, p}^{W}}\right)}
$$

where $d$ is the horizontal distance to each stream segment from the well, $P$ is the total number of points into which a stream segment is subdivided, $n$ is the number of stream segments meeting the stream proximity criteria, and $w$ is a weighting factor used to define web $(w=1)$ or web squared $(w=2)$. We did not conduct a systematic sensitivity analysis of the point spacing in the present study, but exploratory analysis indicated this spacing does not have a large impact on the results.

Only two studies we are aware of compared the performance of depletion apportionment equations. Reeves et al. (2009) compared 9 different methods with results from the Kalamazoo Valley (Michigan) numerical groundwater model and found that the inverse distance approach performed the best, which was then implemented in the Michigan Water Withdrawal Assessment Tool. Zipper et al. (2018a) compared 5 depletion apportionment equations among several different drainage densities, topographic conditions, and recharge rates around Nanaimo, British 
Columbia (Canada), and found that the web squared method best matched results from a numerical model under steady-state conditions.

Of the dozens of existing analytical streamflow depletion models (reviewed in detail by Huang et al., 2018), we selected two for comparison. The first, referred to as the Glover model, is described in Glover \& Balmer (1954). The second, referred to as the Hunt model, is described in Hunt (1999). These two models were selected for comparison due to their widespread application (for example, the Hunt model is used by the Michigan Water Withdrawal Assessment Tool) and contrasting representation of surface water features as described below. Like most analytical models, both the Glover and Hunt models assume a single linear stream oriented perpendicular to the dominant flow field in a homogeneous, isotropic aquifer of infinite horizontal extent with no vertical groundwater flow, among other simplifications.

The Glover method assumes that streams fully penetrate the aquifer and that there is no resistance to flow through the streambed. Based on these assumptions, the Glover model defines streamflow depletion rate, $Q a$, in a stream segment for a given pumping well as:

$$
Q a=Q w * \operatorname{erfc}\left(\sqrt{\frac{S d^{2}}{4 T t}}\right)
$$

where $S$ is the aquifer storage coefficient (specific yield in an unconfined aquifer), $T$ is the aquifer transmissivity, $t$ is the time since the start of pumping, and $d$ and $Q w$ are as defined above.

In contrast, the Hunt method assumes that streams partially penetrate the aquifer and that there is a streambed clogging layer of a finite thickness $\left(b_{r}\right)$ and hydraulic conductivity $\left(K_{r}\right)$ impeding exchange between the aquifer and the stream. Based on these assumptions, the Hunt method defines depletion potential for a given pumping well as:

$$
Q a=Q w * \operatorname{erfc}\left(\sqrt{\frac{S d^{2}}{4 T t}}\right)-\exp \left(\frac{\lambda^{2} t}{4 S T}+\frac{\lambda d}{2 T}\right) \operatorname{erfc}\left(\sqrt{\frac{\lambda^{2} t}{4 S T}}+\sqrt{\frac{S d^{2}}{4 T t}}\right)
$$

where $\lambda$ is the streambed conductance. The streambed conductance is defined as:

$$
\lambda=w_{r} * \frac{K_{r}}{b_{r}}
$$

where $w_{r}$ is the width of the stream segment. The Hunt model will always estimate less depletion than the Glover model, though when the streambed conductance term is large (high $w_{r} * K_{r}$ or small $b_{r}$ ) the two models provide similar output. For both the Glover and Hunt models, we also used the principle of superposition (Jenkins, 1968) to model $Q a$ under intermittent pumping schedules (Section 3.3).

\section{Evaluating analytical depletion function performance}

To evaluate the performance of the analytical depletion functions, we compared them to model output from an archetypal numerical model (described in Section 3.2) based on the Navarro River (California) developed for this study. Archetypal numerical models are simplified representations of real-world environments intended to isolate specific processes of interest 
(Table S1; Zipper et al., 2018a) and have many advantages over calibrated, site-specific models for the evaluation of analytical depletion functions. Most importantly, archetypal numerical models eliminate site-specific complexity unrelated to our research questions to develop generalizable understanding of the importance of process-based representations of streamflow depletion via a comparison between the two modeling approaches. Given these advantages, archetypal models have a long history of use in hydrogeology (Bredehoeft \& Kendy, 2008; Kendy \& Bredehoeft, 2006; Lamontagne-Hallé et al., 2018; Tóth, 1963; Zipper et al., 2017, 251 2018b).

\subsection{Test domain}

We tested our analytical depletion functions using an archetypal numerical model based on the Navarro River Watershed, an $816 \mathrm{~km}^{2}$ watershed in Mendocino County, California, USA (Figure 2; HUC1801010804 in the US National Hydrography Dataset). Streamflow in the Navarro River is highly seasonal, with high flows during the winter rainy season (DecemberApril) and flow sustained primarily by baseflow during the summer dry season (Figure S1; Figure S2). While the Navarro River formerly contained excellent anadromous fish habitat, increases in stream temperature and sedimentation in recent years have contributed to a decline in salmonid populations and subsequent classification by the US Environmental Protection Agency as a "water quality limited water body" (North Coast Regional Water Quality Control Board, 2005).

Human land use in the Navarro River Watershed includes timberland ( 70\%), rangeland ( 20\%), agriculture ( $\sim 5 \%)$, and sparse rural residential (North Coast Regional Water Quality Control Board, 2005). The footprint of irrigated agriculture has expanded over the past 50 years, with vineyards as the largest water users (McGourty et al., 2013). Additionally, the Navarro River Watershed is part of the 'Emerald Triangle' region of California (Humboldt, Mendocino, and Trinity Counties) which is home to widespread cultivation of cannabis, and surface water and groundwater use associated with cannabis cultivation is an emerging management concern (Carah et al., 2015).

\subsection{Numerical model}

The basis of our archetypal numerical model was the Navarro River Watershed (Figure 2), including all adjacent HUC12 watersheds to avoid potential impacts of boundary conditions on the model results. We used the FloPy package for Python (Bakker et al., 2016, 2018) to build a simplified model of the domain using the MODFLOW-NWT finite-difference groundwater flow program (Figure 2b; Niswonger et al., 2011). We simplified domain complexity based on our archetypal modeling approach (Table S1). Our conceptual model for the archetypal model is a homogeneous subsurface with losing streams at high elevations (headwaters) and gaining streams at low elevations (valley bottoms), where homogeneous recharge and both vertical and lateral flow are driven primarily by hydraulic head. As such, our numerical model does not represent potential site-specific features such as subsurface heterogeneity, spatial variability in recharge, or existing groundwater/surface water withdrawals. These simplifications are appropriate for our research questions as the focus of the present study was the comparison of the numerical and analytical approaches for a generalized assessment of sensitivity analysis of analytical depletion functions under transient conditions, rather than a site-specific assessment of the Navarro River Watershed. Ongoing work in other regions is investigating the impacts of 
subsurface heterogeneity, recharge variability, and other site-specific factors on the performance of analytical depletion functions via a comparison with calibrated models.

The domain was discretized at $100 \mathrm{~m} \times 100 \mathrm{~m}$ lateral resolution with 5 vertical layers for a total of 1,112,555 active grid cells. Vertically, the top of the model domain was set to the land surface elevation at the center of each grid cell from the National Elevation Dataset (Figure 2a). Each of the top 4 model layers had a thickness of $20 \mathrm{~m}$, and the bottom layer had a variable thickness with a constant bottom elevation of $100 \mathrm{~m}$ below sea level. By including multiple layers in our MODFLOW model, we are able to test the performance of the analytical depletion functions in settings where vertical flow can occur, which violates an assumption in the analytical models that all flow is horizontal (Glover \& Balmer, 1954; Hunt, 1999), and therefore assess the importance of this and other simplifying assumptions in the analytical models. All model layers were unconfined and capable of drying and re-wetting as necessary. The subsurface was defined as homogeneous with a horizontal saturated hydraulic conductivity $\left(K_{h}\right)$ of $10^{-5} \mathrm{~m} \mathrm{~s}^{-}$ ${ }^{1}$, vertical hydraulic conductivity $\left(K_{v}\right)$ of $10^{-6} \mathrm{~m} \mathrm{~s}^{-1}$, and specific yield $\left(S_{y}\right)$ of 0.1 to represent coarse-grained siliclastic sedimentary rocks typical of the region (Gleeson et al., 2014).

Surface water boundary conditions were defined at all cells including second-order or higher streams in the US National Hydrography dataset (Figure 2) based on the Horton-Strahler order. The stream network within the model domain is divided into 485 segments, of which 175 are part of the Navarro River Watershed and 310 are in the surrounding adjacent watersheds (Figure 2). We used the river package (RIV; Harbaugh et al., 2000) to represent surface water features. For comparison, we also built an archetypal numerical MODFLOW model representing stream features with the surface-water routing package (SFR2; Niswonger \& Prudic, 2005) which routes flow through a network of stream channels and allows for overland flow input to the streams; these results are presented in the supplemental information. We defined the width of each stream segment using a site-specific empirical relationship (Figure S3), estimated riverbed conductance as $10 \%$ of the horizontal hydraulic conductivity of the aquifer, and used a constant river depth of $5 \mathrm{~m}$ due to a lack of data about this parameter. The ocean along the west edge of the domain was a specified constant head boundary (CHB) at an elevation of $0 \mathrm{~m}$. The other lateral model boundaries were all no-flow boundaries except where a RIV or SFR cell reached the edge of the active domain.

Since previous work has shown that spatial variability in recharge rates has a negligible impact on the magnitude and distribution of streamflow depletion (Feinstein et al., 2016) and agriculture represents only 5\% of the land use in the watershed (North Coast Regional Water Quality Control Board, 2005), we elected to simplify recharge dynamics in our archetypal model by ignoring potential return flow from pumping. Groundwater recharge for the domain was spatially uniform and prescribed in the RCH package as $150 \mathrm{~mm} \mathrm{yr}^{-1}$, which is equal to the longterm annual average baseflow (Figure S1). We divided recharge evenly $\left(30 \mathrm{~mm} \mathrm{mo}^{-1}\right)$ among the 5 months constituting the rainy season (December-April; Figure S2), and set recharge to $0 \mathrm{~mm}$ $\mathrm{mo}^{-1}$ during the rest of each year. For the SFR2 package, which allows an overland flow input, we calculated the mean monthly difference between total streamflow and baseflow (Figure S1) and converted this to a volumetric influx for each segment using the direct drainage area to each segment. Since we do not have any field measurements of overland flow, we were not able to evaluate the accuracy of this approach, but during the summer months when baseflow is critical and pumping impacts are most important the overland flow influx was negligible $(<1 \mathrm{~mm}$ month ${ }^{1}$ in July-September and $<10 \mathrm{~mm} \mathrm{month}^{-1}$ in May-October). 
We used a multi-stage spin-up to ensure the groundwater and surface water components of our models had reached a dynamic equilibrium prior to beginning our pumping experiments (Somers et al., 2018; Zipper et al., 2018b). First, we ran a steady-state simulation with no pumping and recharge rates defined as the long-term average annual baseflow (150 $\left.\mathrm{mm} \mathrm{yr}^{-1}\right)$. Using these steady-state results as initial conditions, we then ran the model for a 30-year transient spin-up. To ensure the model reached a dynamic equilibrium, we calculated the annual range in river leakage and found $<0.1 \%$ change between years by the end of the spin-up simulation for both RIV and SFR (Figure S4).

\subsection{Pumping scenarios}

To test the impacts of groundwater pumping on streamflow in a systematic manner, we created a grid of 113 synthetic pumping wells within the Navarro River Watershed which were simulated using the Multi-Node Well package (MNW2; Konikow et al., 2009). Well screens started at the water table elevation from a steady-state simulation and extended $50 \mathrm{~m}$ below this. The MNW2 package allows for pumping from multiple layers if necessary and therefore wells could either be fully contained in one model layer or span up to 3 model layers. These synthetic pumping wells were created by making a grid of pumping wells with $1000 \mathrm{~m}$ spacing (10 grid cells in $\mathrm{x}$ - and $\mathrm{y}$-dimensions), excluding any pumping wells that were placed in grid cells containing stream features, and selecting every $7^{\text {th }}$ well for simulations as a compromise between simulating many wells and minimizing computational time (Figure 2b).

We conducted two transient pumping experiments using these wells to test the performance of the analytical depletion functions: (1) continuous; and (2) intermittent. Both transient experiments were 10 years in length. For the transient continuous experiment, we began pumping in May (the beginning of the dry season; Figure S2) and pumped at a constant rate for 116 months until the end of the 10-year simulation. For the transient intermittent experiment, we turned pumps on during the typical irrigation season of June-October (Bauer et al., 2015). In each experiment, we turned wells on one-at-a-time at a rate of $2.63 \times 10^{-5} \mathrm{~m}^{3} \mathrm{~s}^{-1}$ (600 gallons $\mathrm{day}^{-1}$ ) and compared to a baseline simulation with no pumping at any well. Cannabis cultivation is a concern in the Navarro River Watershed; this pumping rate corresponds to estimated water use for an outdoor cannabis plantation with 100 plants (Bauer et al., 2015). This is larger than the average number of plants at a typical outdoor grow site in the region $(n=45)$, but well below the maximum observed 757 plants (Butsic \& Brenner, 2016). While cannabis water needs were used to define our pumping rate, our results and analysis focused on depletion potential (Section 2) and are therefore broadly applicable to groundwater withdrawals for any purpose.

The primary variable of interest for comparison with analytical depletion functions was depletion potential, or the change in the stream-aquifer flux following pumping normalized by the pumping rate (Table 1; Barlow et al., 2018). To calculate depletion potential from our MODFLOW model output, we calculated the change in net stream-aquifer flux into each stream segment in the Navarro River Watershed while pumping each well relative to a simulation with no pumping (Figure 2; Barlow \& Leake, 2012).

\subsection{Analytical depletion function input data}

Analytical depletion functions require input data related to hydrostratigraphy $(T, S)$, stream characteristics $\left(w, K_{r}, b_{r}\right)$, and well-stream geometry $(d)$. We used the same inputs for our analytical depletion functions and archetypal numerical model, so that our comparison isolates 
the accuracy of the analytical depletion functions, rather than any sort of difference in parameters between models.

For hydrostratigraphic properties, the numerical model uses hydraulic conductivity $(K)$ as input and the analytical models use $T$, which is equal to $K_{h} * b$ (where $b$ is the aquifer thickness). Following Reeves et al. (2009) and Huggins et al. (2018), we defined $b$ for each well-stream combination as the difference in elevation between the steady-state water table elevation and the streambed elevation or the length of the well screen, whichever is greater. Therefore, $b$ can vary for each well-stream combination in our domain. As in the archetypal numerical model, we used a homogeneous $K_{h}\left(=10^{-5} \mathrm{~m} \mathrm{~s}^{-1}\right)$ and $S(=0.1)$ to avoid site-specific complexity.

For stream characteristics, we developed an empirical relationship to predict stream width as a function of the drainage area by manually measuring river width for 20 segments using Google Earth imagery $\left(\mathrm{R}^{2}=0.67\right.$; Figure $\left.\mathrm{S} 3\right)$. Data on $K_{r}$ and $b_{r}$ are rarely available and these inputs are often estimated based on other quantities. Since we did not have field measurements of streambed properties for our domain, we followed Reeves et al. (2009) and estimated $K_{r}$ as $10 \%$ of the aquifer's horizontal hydraulic conductivity $\left(K_{r}=K_{v}=10^{-6} \mathrm{~m} \mathrm{~s}^{-1}\right)$; and $b_{r}$ as a constant thickness of $1 \mathrm{~m}$ to match the numerical model.

We calculated the well-stream distance, $d$, for each well-stream combination as the horizontal Euclidean distance between the well and the closest point on the stream segment. Since we mapped streams as a single polyline feature at the center of the stream channel, this will overestimate the well-stream distance (and therefore an underestimate of streamflow depletion) since the bank of the stream will always be one stream half-width closer to the well than the stream center. In our domain this was not a significant concern because the stream halfwidth was $<5 \%$ of the well-stream distance for $99.6 \%$ of well-stream combinations, but in settings where streams are very wide and/or wells are very close to the stream it may be necessary to use a well-stream distance corresponding to the distance to the streambank.

\subsection{Analytical depletion function output and performance metrics}

The output from the analytical depletion functions is the magnitude of streamflow depletion (expressed as depletion potential) in each stream segment every 10 days, which is calculated separately for every synthetic pumping well. An example for a single well at a single timestep is shown in Figure 3 (as well as Figure S5 and Figure S6), and timeseries output is shown in Figure S7. Since we tested the impacts of 113 wells on 485 stream segments over 10 years, this produced approximately $\sim 20$ million estimates of streamflow depletion for each of the 50 analytical depletion functions ( $\sim 1$ billion total estimates of streamflow depletion).

To synthesize and evaluate these data, we identified four performance metrics intended to capture different aspects of analytical depletion function performance which were calculated at each output timestep. We calculated each of these performance metrics for all analytical depletion functions and compared across different combinations of stream proximity criteria, depletion apportionment equations, and analytical models to determine the sensitivity to each component and identify which analytical depletion function had the best overall performance for our domain.

\section{The performance metrics are:}

1. Spatial distribution of primary impact, defined as accurate identification of the stream segment most affected by a well. We quantified this as the percentage of wells for which the 
stream segment with the greatest depletion potential predicted by the analytical depletion function matched the stream segment with the greatest depletion potential predicted by the MODFLOW model.

2. Magnitude of primary impact, defined as the accuracy of the predicted depletion potential in

where the most affected stream segment. We quantified this as the mean absolute error (MAE) between the depletion potential estimated by the analytical depletion function and the MODFLOW model in the most affected segment, normalized by the range in depletion potential among all wells predicted from the MODFLOW model. We normalized MAE to account for the fact that larger absolute errors are more common but less problematic at higher predictions of depletion potential (e.g. an error of 0.1 is less problematic for a predicted depletion potential of 0.8 than it is for 0.2).

3. Spatial distribution of overall impacts, defined as the accuracy of the predicted depletion potential across the entire domain. We quantified this as the Kling-Gupta Efficiency (KGE; Gupta et al., 2009) between the depletion potential estimated by the analytical depletion function and the depletion potential estimated by the MODFLOW model. The KGE is a hydrological fit metric related to the Nash-Sutcliffe Efficiency which integrates correlation, bias, and variability between the two methods, with 1.0 being a perfect fit and lower values indicating worse performance:

$$
\begin{gathered}
K G E=1-\sqrt{S_{C}(r-1)^{2}+S_{V}(\gamma-1)^{2}+S_{B}(\beta-1)^{2}}, \\
\gamma=\frac{C V_{a}}{C V_{n}}, \\
\beta=\frac{\mu_{a}}{\mu_{n}},
\end{gathered}
$$

$r=$ Pearson correlation coefficient,

$C V=$ coefficient of variation of analytical depletion function $(a)$ or numerical model $(n)$, $\mu=$ mean of analytical depletion function $(a)$ or numerical model $(n)$,

$S_{C}, S_{V}$, and $S_{B}=$ scaling factors used to provide relative weights associated with correlation, variability, and bias, respectively. We set these factors all equal to 1 to weight each type of error equally.

4. Magnitude of overall impacts, defined as the accuracy of the predicted capture fraction, which is equal to the cumulative depletion potential summed across all stream segments from a given well at a given timestep (Barlow et al., 2018). We quantified this as the MAE between the capture fraction estimated by the analytical depletion function and the capture fraction estimated by the MODFLOW model, normalized by the range in capture fraction among all wells from the MODFLOW model.

To evaluate the factors influencing performance, we calculated the proportion of the total mean squared error (MSE) caused by differences in correlation, bias, and variability between the analytical depletion functions and the numerical models, since these different types of error have different management implications (Zipper et al., 2018a). As in Zipper et al. (2018a), we decompose these errors as following Gupta et al. (2009) and Gudmundsson et al. (2012). Specifically, we calculate the proportion of total MSE $\left(M S E_{T}\right)$ caused by differences in correlation $\left(M S E_{C}\right.$; Eq. 11), variability $\left(M S E_{V}\right.$; Eq. 12), and bias (MSE $E_{B}$; Eq. 13): 


$$
\begin{gathered}
M S E_{C}=\frac{2 \sigma_{a} \sigma_{n}(1-r)}{M S E_{T}}, \\
M S E_{V}=\frac{\left(\sigma_{a}-\sigma_{n}\right)^{2}}{M S E_{T}}, \\
M S E_{B}=\frac{\left(\mu_{a}-\mu_{n}\right)^{2}}{M S E_{T}},
\end{gathered}
$$

where $\sigma$ is the population standard deviation.

3.6 Selecting best-performing analytical depletion function and sensitivity analysis

To select the best-performing analytical depletion function, we chose the combination of stream proximity criteria, depletion apportionment equation, and analytical model that performed well across most of these criteria while still providing environmentally conservative estimates of streamflow depletion to avoid overallocating water resources if used in a decision support context.

Since we found that the web and web squared depletion apportionment equations, in combination with the adjacent + expanding stream proximity criteria and Hunt analytical model consistently performed the best (see Section 4.2), we conducted an additional one-at-a-time sensitivity analysis of two parameters: the percent threshold used to define the limit of the adjacent + expanding stream proximity criteria, and the exponent used in the web and web squared depletion apportionment equations. For the percent threshold, we varied over three orders of magnitude: $0.01 \%, 0.1 \%$, and $1 \%$. Smaller thresholds would correspond to a larger domain used in the expanding portion of the stream proximity criteria. For the exponent, we varied the exponent $w$ in Equation 2 from one to three at intervals of 0.5. The web and web squared depletion apportionment equations correspond to $w=1$ and $w=2$, respectively (Figure 1). Larger exponent values give more weight to stream segments which are closer to the well.

We also compared performance metrics for the best-performing analytical depletion function to various landscape attributes and metrics describing well-stream geometry to identify the conditions under which analytical depletion functions were most accurate.

\section{Results and Discussion}

\subsection{Sensitivity analysis of analytical depletion functions}

There is a wide variety of performance across all analytical depletion functions (Figure S8; Figure S9). In the following sections, we explore performance as a function of each stream proximity criteria (Section 2.1), depletion apportionment equation (Section 2.2), and analytical model (Section 2.3).

\subsubsection{Sensitivity to stream proximity criteria}

Stream proximity criteria have relatively little impact on predicting either the spatial distribution (Figure 4a) or the magnitude (Figure 4b) of the primary impact of a pumping well, but a large impact on both the spatial distribution (Figure 4c) and magnitude (Figure 4d) of 
overall impacts. The low sensitivity of primary impacts to stream proximity criteria occurs because the primary impact will typically occur in a stream segment fairly close to the pumping well of interest, and therefore this well will be included regardless of stream proximity criteria. In contrast, the primary function of the stream proximity criteria is defining the total number of

\begin{abstract}
criteria have a large influence on the results encompassing the overall domain.
\end{abstract}
The performance of the stream proximity criteria is strongly affected by the number of stream segments retained. The stream proximity criteria which include the largest number of stream segments (whole domain) has the highest KGE, but also the highest normalized MAE of capture fraction; followed sequentially by criteria with decreasing numbers of stream segments (local area, adjacent + expanding, adjacent, and expanding). As the time increases and the number of stream segments included in the expanding criteria increases, it begins to perform better than the adjacent stream proximity criteria (Figure 4c). Despite the sensitivity to the number of stream segments, overall performance changes only slightly when varying the percent depletion potential threshold used to define the stream segments included in the expanding stream proximity criteria (Figure S10). Overall, a 1\% threshold for the adjacent + expanding stream proximity criteria performs the best throughout the entire simulated period.

\title{
4.1.2 Sensitivity to depletion apportionment equation
}

In contrast to the stream proximity criteria, the depletion apportionment equations have a strong impact on the spatial distribution of the primary impact, and the web and web squared methods correctly identify the most affected segment substantially better than the other depletion apportionment equations tested (Figure 5a). The accuracy of web and web squared is $>80 \%$ in the first several years before asymptoting at $\sim 75 \%$ in the continuous pumping experiment and $\sim 90 \%$ in the intermittent pumping experiment, meaning that these depletion apportionment equations accurately identify the most affected stream segment most of the time.

Similarly, the web and web squared approaches are also the best at estimating the magnitude of impacts in the most affected segment (Figure 5b). Normalized MAE is $\sim 0.05-0.15$ throughout the continuous pumping experiment (meaning $\sim 5-15 \%$ of the observed range in depletion potential). There is a seasonal pattern in performance in the intermittent pumping experiment, with normalized MAE of $\sim 0.05-0.10$ during the pumping period and normalized MAE of $\sim 0.15-0.20$ when the wells are shut off. This variability in seasonal performance is driven primarily by changes in the observed range of depletion potentials between the two seasons, with a larger range when pumps are turned on during the summer.

The spatial distribution of overall impacts, as quantified using the KGE across all stream segments (Figure 5c), indicate a decay in performance through time for all methods. Early in the simulations, KGE is relatively high since depletion is primarily concentrated in the segments closest to the well. As time goes on and impacts become more diffuse, the overall performance decreases to different degrees among the different methods and no analytical depletion function has a high overall KGE. After $\sim 1.5$ years, the web and inverse distance approaches plateau at a $\mathrm{KGE}$ of $\sim 0$, while the web squared and inverse distance squared approaches plateau at a KGE of $\sim-0.5$. Unlike the distance-based approaches, the performance of the area-based Thiessen Polygon method continues to degrade through time. 
The magnitude of overall impacts shows consistent patterns across all depletion apportionment equations (Figure 5d). Normalized MAE of predicted capture fraction increases through time, from $\sim 0.10$ at the start of the continuous pumping experiment to $\sim 0.50$ for the worst-performing metrics by the end. The various depletion apportionment equations diverge after approximately 3 years and the difference between equations increases through time. Normalized MAE of capture fraction in the intermittent pumping experiment has a similar increasing trajectory to the continuous pumping experiment, and a strong seasonal pattern as observed in the normalized MAE of the most affected segment (Figure 5b).

To demonstrate the difference between analytical depletion functions and the traditional use of analytical streamflow depletion models, we also plot the performance of the Hunt analytical model without considering stream proximity criteria or depletion apportionment equations (i.e., assuming all impacts are in the closest stream segment to the well). These results, shown as a dashed line in Figure 5, demonstrate that using analytical depletion functions substantially improves predictions of the spatial distribution of primary impacts (Figure 5a), the magnitude of primary impacts (Figure 5b), and the spatial distribution of the overall impacts (Figure 5c), with a slight decrease in performance in the magnitude of overall impacts (Figure 5d). These results indicate that, in the real-world stream network geometries tested here, analytical depletion functions are preferable to analytical models for predictions of streamflow depletion due to groundwater pumping.

\subsubsection{Sensitivity to analytical model}

As with the stream proximity criteria, the performance of the analytical models at identifying the most affected segment is virtually identical (Figure 6a). Unlike the stream proximity criteria, however, the two analytical models differ in their prediction of the magnitude of depletion in this segment: the Hunt method has a consistently lower normalized MAE in the most affected segment. Given that analytical depletion functions tend to overpredict depletion potential in the most affected segment (Figure S7), the lower error with the Hunt model indicates that the consideration of the streambed properties leads to lower predicted depletion potential which better matches the MODFLOW output. However, unlike the differences between depletion apportionment equations and stream proximity criteria, all performance metrics show a converging trend between the two analytical models towards the end of the continuous pumping experiment (Figure 6). The converging trend indicates that, under transient conditions, the relative importance of streambed conductance decreases as estimated depletion potential increases and the model approaches a dynamic steady-state which is insensitive to conductivity.

While our results indicate that the sensitivity of modeled depletion potential to the choice of analytical model is relatively low, previous work has demonstrated that the streambed conductance exerts a large influence on the accuracy of analytical model results (Sophocleous et al., 1995; Spalding \& Khaleel, 1991). In settings with a lower streambed conductance (e.g. lower streambed hydraulic conductivity or a thicker streambed clogging layer), the difference between the Hunt and Glover models would be greater. Unfortunately, streambed conductance is challenging to measure and therefore often estimated based on aquifer properties or treated as a calibration parameter in both numerical and analytical approaches. However, in reality streambed conductance is often highly heterogeneous and incorrect estimates can lead to errors in estimated streamflow depletion (Fleckenstein et al., 2006; Irvine et al., 2012; Lackey et al., 2015). In this context, analytical depletion functions can be used to identify stream segments 
which may have high depletion potential due to groundwater pumping, and guide further field data collection to better constrain parameter estimates for either numerical or analytical approaches.

\subsection{Selecting best analytical depletion function}

Among our 50 analytical depletion functions tested, there was no single combination of stream proximity criteria, depletion apportionment equation, and analytical model that performed the best for all the performance metrics. Therefore, we used the degree to which a performance metric was sensitive to that component of the analytical depletion functions to guide the selection of the best overall analytical depletion function.

Stream proximity criteria had the largest influence on the spatial distribution and magnitude of overall impacts (Section 4.1.1). However, changing stream proximity criteria had opposite impacts on the spatial distribution and magnitude of primary impacts, where the proximity criteria that produced the best spatial distribution of primary impacts (Figure 4c) led to the worst predictions of magnitude of primary impacts (Figure $4 \mathrm{~d}$ ). Therefore, we selected the adjacent + expanding stream proximity criteria as best overall, which was in the middle for both performance metrics and therefore balances these two metrics.

The depletion apportionment equations had the largest influence on the spatial distribution of primary impacts (Section 4.1.2), and the web and web squared approaches had a very similar performance which was consistently better than the other depletion apportionment equations (Figure 5a). To aid in our decision, we also compared additional web exponents ( $w$ in Equation 4) ranging from one to three. As the exponent increased, the normalized MAE and bias of depletion potential predictions for the most affected segment also increased while the KGE across all segments decreased (Figure 7). From a management perspective, analytical depletion functions are most useful if they provide conservative estimates of depletion (overestimates) to avoid potentially over-allocating water resources (Zipper et al., 2018a). We find that all web exponents overestimate depletion shortly after the start of pumping in the continuous pumping experiment, and all except web provide initially conservative estimates for the intermittent pumping experiment (Figure 7b). While the web depletion apportionment equation performed better averaged over the entire timeseries on several performance metrics (Table S2), the web squared depletion apportionment equation produces the least biased estimates among the exponents providing conservative results.

Finally, the analytical model had the largest influence on the magnitude of primary impacts (Section 4.1.3), and the Hunt analytical model consistently provided better predictions than the Glover model throughout the entirety of our simulations.

Therefore, we conclude that the best-performing analytical depletion function is the combination of the adjacent + expanding stream proximity criteria using a $1 \%$ threshold (Figure 4; Figure S10), the web squared depletion apportionment equation (Figure 5; Figure 7), and the Hunt model (Figure 6). Compared to all other analytical depletion functions, the adjacent + expanding \& web squared \& Hunt approach provides a conservative estimate of depletion while performing among the best for each of our four performance metrics. 
The selected analytical depletion function (adjacent + expanding stream proximity criteria, web squared depletion apportionment equation, and Hunt analytical model) does particularly well at estimating the primary impacts of pumping, which tend to be of most concern to managers. The best-performing approach correctly identifies the most affected stream segment $\geq 70 \%$ of the time there are substantial impacts $(Q d>0.05)$ in the continuous pumping experiment and $\geq 85 \%$ of the time in the intermittent pumping experiment (Figure 4a, Figure 5a, and Figure 6a). Additionally, the magnitude of primary impact is well-predicted, with a normalized MAE in most affected segment $\leq 0.15$ in the continuous pumping experiment and $\leq$ 0.20 in the intermittent pumping experiment (Figure 4b, Figure 5b, and Figure 6b). Error in the magnitude of primary impacts is characterized by a positive bias (Figure 7b), which is most pronounced at high levels of depletion (Figure 8a). This positive bias indicates that the selected analytical depletion function provides a conservative estimate of depletion in strongly affected stream segments, which is important to avoid over-allocating water resources.

Performance metrics describing predictions of the distribution and magnitude of domainwide depletion are less encouraging than those describing the primary impacts. For the spatial distribution of overall impacts the selected analytical depletion function performs the worst relative to other options, with KGE across all stream segments $\geq 0$ only during the first year of the transient pumping experiments (Figure $4 c$, Figure 5c, and Figure 6c). However, the magnitude of overall impacts is still predicted fairly accurately, with the normalized MAE of total capture fraction $<0.40$ throughout the continuous and intermittent pumping experiments (Figure 4d, Figure 5d, and Figure 6d), with normalized MAE $<0.20$ for the first 2 years after the start of pumping. Like the primary impacts, the analytical depletion function provides a conservative estimate of depletion potential, with errors characterized by overprediction of depletion in heavily affected segments (Figure 8a).

Error decomposition (Gudmundsson et al., 2012; Gupta et al., 2009) indicates that the contributions of different factors to overall error are relatively stable through time (Figure 8b; Figure S11). Imperfect correlation is the cause of $\sim 65 \%$ of the total mean squared error for the most affected segment, with variability contributing most of the other $\sim 35 \%$ (Figure 8b; Figure S11). Bias was not a dominant source of error, despite the observed overprediction at high levels of depletion potential; this is because the contribution of bias to overall mean squared error is calculated using the difference between the mean analytical and mean MODFLOW depletion potential, and the positive bias at high levels of depletion potential is balanced out by a negative bias at low levels of depletion potential caused by the conservation of mass (Figure 8a). This is consistent with the steady-state results from Zipper et al. (2018a), which found that the web squared depletion apportionment equation had a mix of primarily correlation- and variabilitydriven error. The management implications of these different types of error are discussed in Zipper et al. (2018a); having a relatively balanced error profile between variability and correlation indicates that both the overall mean depletion and the spatial patterns of depletion will be captured by the analytical depletion function.

To determine whether our results were sensitive to the construction of the MODFLOW model, we also compared each analytical depletion function to results from separate MODFLOW models constructed using the SFR2 package for stream features instead of the RIV package (Figure S9). While 3 of the 4 performance metrics are comparable whether the RIV or SFR2 packages are used, the analytical depletion functions do not match the most affected 
segment as frequently when compared to the SFR 2 models, asymptoting at $\sim 60-65 \%$ for both the continuous and intermittent pumping experiments.

Performance of the analytical depletion functions varies in response to several factors describing landscape position and well-stream geometry. Spatially, performance tends to be worst in the northeastern portion of the domain near the watershed boundary (Figure 9a). This region corresponds with some of the highest elevation portions of the watershed (Figure 2). Across all wells, performance is correlated with several elevation-based metrics including the land surface elevation, water table elevation, and water table depth. Of these, normalized MAE has the strongest linear relationship with steady-state water table elevation (Figure 9b), with decreased performance at higher water table elevations $\left(R^{2}=0.29, \mathrm{p}<10^{-5}\right)$.

Additionally, both the lateral and vertical distance between the well and the stream segment influence analytical depletion function skill. The lateral stream-well distance has a strong positive correlation with normalized $\operatorname{MAE}\left(\mathrm{R}^{2}=0.72, \mathrm{p}<10^{-5}\right)$, though at well-stream distances $<2.7 \mathrm{~km}$ performance is insensitive to changes in well-stream distance (Figure 9c). Interestingly, we find the opposite relationship between normalized MAE and lateral well-stream distance when comparing to the MODFLOW model built using the SFR2 package (Figure S12). We attribute the change in the direction of the relationship between normalized MAE and wellstream distance to the difference in stream representation between these two MODFLOW packages. In the numerical model built using the SFR2 package, when a well is very close to a stream segment and causes a lot of depletion, it leads to a more substantial change in the head in the stream, potentially including stream drying in severe cases. This dynamic is not captured by the analytical models which assume negligible change in stream head and an infinite supply of water, analogous to the RIV package. Therefore, analytical depletion functions may not be wellsuited to intermittent streams which are vulnerable to groundwater pumping, though if it is known a priori which stream segments are dry at certain times, they can be excluded from stream proximity criteria.

Similarly, the analytical depletion functions perform best when the elevation difference between the well and stream is small, with particularly large decreases when the top of the well is at a lower elevation than the stream segment, potentially indicating a steep topographic gradient between the stream and the well (Figure 9d). Finally, there is a negative correlation between analytical depletion function performance (normalized MAE) and stream segment length for stream segments $<\sim 1 \mathrm{~km}$ in length, while performance is insensitive to stream segment length once segment length exceeds $1 \mathrm{~km}$ (Figure 9e). Poor performance in short streams was also observed under steady-state conditions in Zipper et al. (2018a).

4.5 Utility, limitations, and future research needs for analytical depletion functions

Our results indicate that analytical depletion functions are likely to be a useful tool for quantifying streamflow depletion resulting from an existing and/or proposed well, thus allowing managers to assess pumping impacts on streamflow in settings where numerical models are not available (Watson et al., 2014). Notably, the analytical depletion functions are successfully able to identify which stream segment will be most affected by a pumping well most of the time and provide accurate predictions of the magnitude of its impact (Section 4.3). Comparing across the various factors influencing performance (Section 4.4), we find that the analytical depletion 
functions are most likely to be accurate for wells placed in relatively flat areas with a nearsurface water table and within a few kilometers of a downgradient perennial stream. Conveniently, these factors also describe locations which are often well-suited to agriculture, such as alluvial valleys, indicating that the analytical depletion functions are likely to be most effective in the locations where they are most needed. For instance, in the Navarro River Watershed much of the agriculture is concentrated in the lowlands of the Anderson Valley around Boonville, which is where analytical depletion functions perform the best (Figure 9a).

From a management perspective, the primary utility of analytical depletion functions is likely to be as a screening tool for impacts of pumping wells, rather than a replacement for calibrated numerical models. By providing rapid estimates of streamflow depletion which can be used to identify areas of potential concern, adding analytical depletion functions to the toolbox of water managers and scientists will allow more efficient prioritization of time-intensive efforts such as field data collection or the development of calibrated numerical models. One example for how these tools may be implemented in a decision support context is provided by Huggins et al. (2018), who show that depletion apportionment equations combined with analytical models can provide rapid network-wide assessment of streamflow depletion when integrated with existing online tools.

While we tested a variety of analytical depletion functions, our analysis was not exhaustive and in some settings it may be necessary to go beyond the combinations of stream proximity criteria, depletion apportionment equations, and analytical models considered here. For instance, in domains where semi-confined ('leaky') aquifers represent a significant source of water to wells, analytical depletion function performance would likely be improved by using an analytical model specifically designed for these settings (Butler et al., 2007; Hunt, 2003; Zlotnik, 2004; Zlotnik \& Tartakovsky, 2008), rather than the Hunt and Glover models used here. A recent review provides a useful flow-chart for analytical model selection (Huang et al., 2018). However, additional work is needed to test the integration of these analytical models with depletion apportionment equations.

Alternately, in some settings more complex analytical models may eliminate the need for stream proximity criteria and depletion apportionment equations. For instance, in wedge-shaped aquifers bounded by approximately linear surface water features which are commonly found at the confluence of two streams, Yeh et al. (2008) provide a fully analytical solution which does not require the use of depletion apportionment equations. While the Yeh et al. (2008) solution approach considers only two stream segments and therefore does not account for potential factors such as underflow, it has the potential to provide additional theory-based evaluations of the performance of analytical depletion functions in controlled modelling experiments. Furthermore, all of our experiments turned wells on one-at-a-time, and future work is needed to examine the cumulative impacts of multiple pumping wells, as the total impact from multiple wells may not be equal to the sum of the effects of individual wells (Ahlfeld et al., 2016; Schneider et al., 2017).

\section{Conclusions}

In this study, we evaluated the performance of 50 analytical depletion functions to quantify the sensitivity of analytical depletion functions to the choice of depletion apportionment equations, stream proximity criteria, and analytical model under transient conditions; and identify factors describing the landscape and well-stream geometry that influence the 
performance of analytical depletion functions. We found that the analytical depletion functions proximity criteria, and the least sensitive to the choice of analytical model under the conditions studied. The web and web squared depletion apportionment equations, which consider stream geometry, were best able to predict which stream segment would be most affected by a well, as well as the magnitude of overall impacts.

The analytical depletion function which performed the best combined the adjacent + expanding stream proximity criteria with the web squared depletion apportionment equation and the Hunt analytical model. This analytical depletion function correctly identified the stream segment most affected by a well $>70 \%$ and $>85 \%$ of the time under continuous and intermittent pumping conditions, respectively, with a mean absolute error $<20 \%$ of the range in observed depletion potential. From an application perspective, analytical depletion functions performed the best in areas with little topographic relief, when wells were within $\sim 3 \mathrm{~km}$ of downgradient perennial streams, and when stream segments are at least $\sim 1 \mathrm{~km}$ in length.

Overall, these results indicate that analytical depletion functions are likely to be a useful management decision support tool in locations where calibrated numerical models are unavailable, though additional research is needed to test their accuracy in a variety of hydrogeological settings. Analytical depletion functions can be used to test whether proposed pumping wells might negatively impact streams and used to prioritize more complex field investigations and modelling studies in higher risk locations. We show that analytical depletion functions provide more accurate predictions of the distribution and magnitude of pumping impacts than analytical models alone, since the stream proximity criteria and depletion apportionment equations can distribute pumping impacts within a stream network. Given their low computational requirements, analytical depletion functions are particularly well-suited for integration with web-based tools for real-time screening and decision support (Huggins et al., 2018), where the analytical depletion functions can be integrated with diverse geospatial datasets to provide rapid, accurate, and site-specific estimates of streamflow depletion.

\section{Acknowledgments and Data}

We appreciate helpful suggestions and resources from Vitaly Zlotnik, Hund-Der Yeh, Ya-Chi Chang, and Qiang Li, as well as reviews by Thomas Harter, Gus Tolley, and two anonymous reviewers. Data and code are available via GitHub (https://github.com/samzipper/TNCPilotProject) during the review process and will be posted to a repository at paper acceptance. This work was funded by a Natural Sciences and Engineering Research Council Collaborative Research and Development Grant (NSERC CRD) to the University of Victoria and Foundry Spatial. We would like to also thank the S.D. Bechtel, Jr. Foundation for their philanthropic financial support to The Nature Conservancy's ongoing research on sustainable groundwater management. All analyses were performed using R 3.5.1 (R Core Team, 2019) and Python (Python Software Foundation, 2018). Graphics were made with InkScape (The Inkscape Team, 2015), ggplot2 (Wickham, 2009), and ggtern (Hamilton, 2017). Analytical depletion functions are available as part of the streamDepletr package for R (Zipper, 2019). 


\section{References}

Ahlfeld, D. P., Schneider, J. C., \& Spalding, C. P. (2016). Effects of nonlinear model response on allocation of streamflow depletion: exemplified by the case of Beaver Creek, USA. Hydrogeology Journal, 24(7), 1835-1845. https://doi.org/10.1007/s10040-016-1438-3

Bakker, M., Post, V., Langevin, C. D., Hughes, J. D., White, J. T., Starn, J. J., \& Fienen, M. N. (2016). Scripting MODFLOW Model Development Using Python and FloPy. Groundwater, 54(5), 733-739. https://doi.org/10.1111/gwat.12413

Bakker, M., Post, V., Langevin, C. D., Hughes, J. D., White, J. T., Starn, J. J., \& Fienen, M. N. (2018). FloPy (Version 3.29). Retrieved from http://dx.doi.org/10.5066/F7BK19FH

Barlow, P. M., Leake, S. A., \& Fienen, M. N. (2018). Capture versus Capture Zones: Clarifying Terminology Related to Sources of Water to Wells. Groundwater. https://doi.org/10.1111/gwat.12661

Barlow, P. M., \& Leake, S. A. (2012). Streamflow depletion by wells--Understanding and managing the effects of groundwater pumping on streamflow (No. Circular 1376). Reston VA: U.S. Geological Survey.

Bauer, S., Olson, J., Cockrill, A., Hattem, M. van, Miller, L., Tauzer, M., \& Leppig, G. (2015). Impacts of Surface Water Diversions for Marijuana Cultivation on Aquatic Habitat in Four Northwestern California Watersheds. PLOS ONE, 10(3), e0120016. https://doi.org/10.1371/journal.pone.0120016

Bredehoeft, J. D., Papadopulos, S. S., \& Cooper, H. H. (1982). Groundwater: The water budget myth. Scientific Basis of Water Resource Management, 51, 57.

Bredehoeft, J., \& Kendy, E. (2008). Strategies for Offsetting Seasonal Impacts of Pumping on a Nearby Stream. Ground Water, 46(1), 23-29. https://doi.org/10.1111/j.1745-6584.2007.00367.x

Butler, J. J., Zhan, X., \& Zlotnik, V. A. (2007). Pumping-Induced Drawdown and Stream Depletion in a Leaky Aquifer System. Ground Water, 45(2), 178-186. https://doi.org/10.1111/j.17456584.2006.00272.x

Butsic, V., \& Brenner, J. C. (2016). Cannabis (Cannabis sativa or C. indica) agriculture and the environment: a systematic, spatially-explicit survey and potential impacts. Environmental Research Letters, 11(4), 044023. https://doi.org/10.1088/1748-9326/11/4/044023

Carah, J. K., Howard, J. K., Thompson, S. E., Gianotti, S., G, A., Bauer, S. D., ... Power, M. E. (2015). High Time for Conservation: Adding the Environment to the Debate on Marijuana Liberalization. BioScience, 65(8), 822-829. https://doi.org/10.1093/biosci/biv083

Feinstein, D. T., Fienen, M. N., Reeves, H. W., \& Langevin, C. D. (2016). A Semi-Structured MODFLOW-USG Model to Evaluate Local Water Sources to Wells for Decision Support. Groundwater, 54(4), 532-544. https://doi.org/10.1111/gwat.12389

Fienen, M. N., Bradbury, K. R., Kniffin, M., \& Barlow, P. M. (2018). Depletion Mapping and Constrained Optimization to Support Managing Groundwater Extraction. Groundwater, 56(1), 18 31. https://doi.org/10.1111/gwat.12536

Fienen, M. N., Nolan, B. T., \& Feinstein, D. T. (2016). Evaluating the sources of water to wells: Three techniques for metamodeling of a groundwater flow model. Environmental Modelling \& Software, 77, 95-107. https://doi.org/10.1016/j.envsoft.2015.11.023

Fleckenstein, J. H., Niswonger, R. G., \& Fogg, G. E. (2006). River-Aquifer Interactions, Geologic Heterogeneity, and Low-Flow Management. Groundwater, 44(6), 837-852. https://doi.org/10.1111/j.1745-6584.2006.00190.x

Gleeson, T., Moosdorf, N., Hartmann, J., \& van Beek, L. P. H. (2014). A glimpse beneath earth's surface: GLobal HYdrogeology MaPS (GLHYMPS) of permeability and porosity. Geophysical Research Letters, 41(11), 2014GL059856. https://doi.org/10.1002/2014GL059856

Gleeson, T., \& Richter, B. (2017). How much groundwater can we pump and protect environmental flows through time? Presumptive standards for conjunctive management of aquifers and rivers. River Research and Applications. https://doi.org/10.1002/rra.3185 
834

835

836

837

838

839

840

841

842

843

844

845

846

847

848

849

850

851

852

853

854

855

856

857

858

859

860

861

862

863

864

865

866

867

868

869

870

871

872

873

874

875

876

877

878

879

880

881

882

883

884

Glover, R. E., \& Balmer, G. G. (1954). River depletion resulting from pumping a well near a river. Eos, Transactions American Geophysical Union, 35(3), 468-470. https://doi.org/10.1029/TR035i003p00468

Gudmundsson, L., Wagener, T., Tallaksen, L. M., \& Engeland, K. (2012). Evaluation of nine large-scale hydrological models with respect to the seasonal runoff climatology in Europe. Water Resources Research, 48(11), W11504. https://doi.org/10.1029/2011WR010911

Gupta, H. V., Kling, H., Yilmaz, K. K., \& Martinez, G. F. (2009). Decomposition of the mean squared error and NSE performance criteria: Implications for improving hydrological modelling. Journal of Hydrology, 377(1), 80-91. https://doi.org/10.1016/j.jhydrol.2009.08.003

Hamilton, D. A., \& Seelbach, P. W. (2011). Michigan's water withdrawal assessment process and internet screening tool. Fisheries Division Special Report, 55.

Hamilton, N. (2017). ggtern: An Extension to "ggplot2", for the Creation of Ternary Diagrams (Version 2.2.1). Retrieved from https://CRAN.R-project.org/package=ggtern

Harbaugh, A. W., Banta, E. R., Hill, M. C., \& McDonald, M. G. (2000). MODFLOW-2000, The U.S. Geological Survey Modular Ground-Water Model - User Guide to Modularization Concepts and the Ground-Water Flow Process (No. 2000-92). U.S. Geological Survey. Retrieved from https://pubs.er.usgs.gov/publication/ofr200092

Huang, C.-S., Yang, T., \& Yeh, H.-D. (2018). Review of analytical models to stream depletion induced by pumping: Guide to model selection. Journal of Hydrology, 561, 277-285. https://doi.org/10.1016/j.jhydrol.2018.04.015

Huggins, X., Gleeson, T., Eckstrand, H., \& Kerr, B. (2018). Streamflow Depletion Modeling: Methods for an Adaptable and Conjunctive Water Management Decision Support Tool. JAWRA Journal of the American Water Resources Association. https://doi.org/10.1111/1752-1688.12659

Hunt, B. (1999). Unsteady Stream Depletion from Ground Water Pumping. Ground Water, 37(1), 98102. https://doi.org/10.1111/j.1745-6584.1999.tb00962.x

Hunt, B. (2003). Unsteady Stream Depletion when Pumping from Semiconfined Aquifer. Journal of Hydrologic Engineering, 8(1), 12-19. https://doi.org/10.1061/(ASCE)1084-0699(2003)8:1(12)

Hunt, B. (2014). Review of Stream Depletion Solutions, Behavior, and Calculations. Journal of Hydrologic Engineering, 19(1), 167-178. https://doi.org/10.1061/(ASCE)HE.1943-5584.0000768

Irvine, D. J., Brunner, P., Franssen, H.-J. H., \& Simmons, C. T. (2012). Heterogeneous or homogeneous? Implications of simplifying heterogeneous streambeds in models of losing streams. Journal of Hydrology, 424-425, 16-23. https://doi.org/10.1016/j.jhydrol.2011.11.051

Jenkins, C. T. (1968). Techniques for Computing Rate and Volume of Stream Depletion by Wells. Ground Water, 6(2), 37-46. https://doi.org/10.1111/j.1745-6584.1968.tb01641.x

Kendy, E., \& Bredehoeft, J. D. (2006). Transient effects of groundwater pumping and surface-waterirrigation returns on streamflow. Water Resources Research, 42(8), W08415. https://doi.org/10.1029/2005WR004792

Kollet, S. J., Zlotnik, V. A., \& Ledder, G. (2002). "A Stream Depletion Field Experiment," by Bruce Hunt, Julian Weir, and Bente Clausen, March-April 2001 issue, v. 39, no. 2: 283-289. Ground Water, 40(4), 448-449. https://doi.org/10.1111/j.1745-6584.2002.tb02523.x

Konikow, L. F., Hornberger, G. Z., Halford, K. J., \& Hanson, R. T. (2009). Revised Multi-Node Well (MNW2) Package for MODFLOW Ground-Water Flow Model (No. USGS Techniques and Methods 6-A30) (p. 67). Reston VA. Retrieved from https://pubs.usgs.gov/tm/tm6a30/

Lackey, G., Neupauer, R. M., \& Pitlick, J. (2015). Effects of Streambed Conductance on Stream Depletion. Water, 7(1), 271-287. https://doi.org/10.3390/w7010271

Lamontagne-Hallé, P., McKenzie, J. M., Kurylyk, B. L., \& Zipper, S. C. (2018). Changing groundwater discharge dynamics in permafrost regions. Environmental Research Letters, 13(8), 084017. https://doi.org/10.1088/1748-9326/aad404

Larsen, L. G., \& Woelfle-Erskine, C. (2018). Groundwater is key to salmonid persistence and recruitment in intermittent Mediterranean-climate streams. Water Resources Research. https://doi.org/10.1029/2018WR023324

Zipper et al. | Analytical Depletion Functions | Page 22 of $\mathbf{4 8}$ 
McGourty, G., Lewis, D. J., Harper, J., Elkins, R., Metz, J., Nosera, J., ... Sanford, R. (2013). Meeting irrigated agriculture water needs in the Navarro River Watershed. Ukiah, California: University of California Cooperative Extension Mendocino County. Retrieved from http://cemendocino.ucanr.edu/files/166809.pdf

Niswonger, R. G., Panday, S., \& Ibaraki, M. (2011). MODFLOW-NWT, A Newton Formulation for MODFLOW-2005 (No. U.S. Geological Survey Techniques and Methods 6-A37) (p. 44). Reston, VA. Retrieved from https://pubs.usgs.gov/tm/tm6a37/

Niswonger, R. G., \& Prudic, D. E. (2005). Documentation of the Streamflow-Routing (SFR2) Package to Include Unsaturated Flow Beneath Streams - A Modification to SFR1 (USGS Numbered Series No. 6-A13) (p. 57). U.S. Geological Survey. Retrieved from http://pubs.er.usgs.gov/publication/tm6A13

North Coast Regional Water Quality Control Board. (2005). Watershed Planning Chapter. Santa Rosa, CA. Retrieved from https://www.waterboards.ca.gov/northcoast/water_issues/programs/wpc/wpc.pdf

Perkin, J. S., Gido, K. B., Falke, J. A., Fausch, K. D., Crockett, H., Johnson, E. R., \& Sanderson, J. (2017). Groundwater declines are linked to changes in Great Plains stream fish assemblages. Proceedings of the National Academy of Sciences, 114(28), 7373-7378. https://doi.org/10.1073/pnas.1618936114

Python Software Foundation. (2018). Python Language Reference, version 3.6. Retrieved from http://www.python.org

R Core Team. (2019). R: A language and environment for statistical computing (Version 3.6.0). Vienna, Austria: R Foundation for Statistical Computing. Retrieved from https://www.R-project.org/

Reeves, H. W., Hamilton, D. A., Seelbach, P. W., \& Asher, A. J. (2009). Ground-water-withdrawal component of the Michigan water-withdrawal screening tool (Scientific Investigations Report No. 2009-5003) (p. 36). Reston VA: U.S. Geological Survey. Retrieved from https://pubs.usgs.gov/sir/2009/5003/

Reeves, H. W., Nicholas, J. R., Seelbach, P. W., \& Hamilton, D. A. (2010). Management of Surface Water and Groundwater Withdrawals to Maintain Environmental Stream Flows in Michigan. In Watershed Management Conference 2010. https://doi.org/10.1061/41143(394)37

Rohde, M. M., Froend, R., \& Howard, J. (2017). A Global Synthesis of Managing Groundwater Dependent Ecosystems Under Sustainable Groundwater Policy. Groundwater, n/a-n/a. https://doi.org/10.1111/gwat.12511

Rohde, M. M., Matsumoto, S., Howard, J., Liu, S., Riege, L., \& Remson, E. J. (2018). Groundwater Dependent Ecosystems under the Sustainable Groundwater Management Act: Guidance for Preparing Groundwater Sustainability Plans. San Francisco, CA: The Nature Conservancy.

Schneider, J. C., Ahlfeld, D. P., \& Spalding, C. P. (2017). Allocation of Streamflow Depletion Impacts under Nonlinear Conditions. JAWRA Journal of the American Water Resources Association, 53(3), 697-706. https://doi.org/10.1111/1752-1688.12525

Singh, S. K. (2009). Flow Depletion Induced by Pumping Well from Stream Perpendicularly Intersecting Impermeable/Recharge Boundary. Journal of Irrigation and Drainage Engineering, 135(4), 499-504. https://doi.org/10.1061/(ASCE)IR.1943-4774.0000095

Somers, L. D., McKenzie, J. M., Zipper, S. C., Mark, B. G., Lagos, P., \& Baraer, M. (2018). Does hillslope trenching enhance groundwater recharge and baseflow in the Peruvian Andes? Hydrological Processes, 32(3), 318-331. https://doi.org/10.1002/hyp.11423

Sophocleous, M., Koussis, A., Martin, J. L., \& Perkins, S. P. (1995). Evaluation of Simplified StreamAquifer Depletion Models for Water Rights Administration. Ground Water, 33(4), 579-588. https://doi.org/10.1111/j.1745-6584.1995.tb00313.x

Spalding, C. P., \& Khaleel, R. (1991). An evaluation of analytical solutions to estimate drawdowns and stream depletions by wells. Water Resources Research, 27(4), 597-609. https://doi.org/10.1029/91WR00001

The Inkscape Team. (2015). Inkscape (Version 0.91). Retrieved from https://inkscape.org/en/ 
Tóth, J. (1963). A theoretical analysis of groundwater flow in small drainage basins. Journal of Geophysical Research, 68(16), 4795-4812. https://doi.org/10.1029/JZ068i016p04795

Watson, K. A., Mayer, A. S., \& Reeves, H. W. (2014). Groundwater Availability as Constrained by Hydrogeology and Environmental Flows. Groundwater, 52(2), 225-238. https://doi.org/10.1111/gwat.12050

White, E. K., Peterson, T. J., Costelloe, J., Western, A. W., \& Carrara, E. (2016). Can we manage groundwater? A method to determine the quantitative testability of groundwater management plans. Water Resources Research, 52(6), 4863-4882. https://doi.org/10.1002/2015WR018474

Wickham, H. (2009). ggplot2: Elegant Graphics for Data Analysis. Springer-Verlag New York. Retrieved from http://ggplot2.org

Yeh, H.-D., Chang, Y.-C., \& Zlotnik, V. A. (2008). Stream depletion rate and volume from groundwater pumping in wedge-shape aquifers. Journal of Hydrology, 349(3), 501-511. https://doi.org/10.1016/j.jhydrol.2007.11.025

Zipper, S. C. (2019). streamDepletr: Estimate Streamflow Depletion Due to Groundwater Pumping (Version R package version 0.1.0). Retrieved from https://CRAN.Rproject.org/package $=$ streamDepletr

Zipper, S. C., Dallemagne, T., Gleeson, T., Boerman, T. C., \& Hartmann, A. (2018a). Groundwater pumping impacts on real stream networks: Testing the performance of simple management tools. Water Resources Research, 54(8), 5471-5486. https://doi.org/10.1029/2018WR022707

Zipper, S. C., Soylu, M. E., Kucharik, C. J., \& Loheide II, S. P. (2017). Quantifying indirect groundwatermediated effects of urbanization on agroecosystem productivity using MODFLOW-AgroIBIS (MAGI), a complete critical zone model. Ecological Modelling, 359, 201-219. https://doi.org/10.1016/j.ecolmodel.2017.06.002

Zipper, S. C., Lamontagne-Hallé, P., McKenzie, J. M., \& Rocha, A. V. (2018b). Groundwater controls on post-fire permafrost thaw: Water and energy balance effects. Journal of Geophysical Research: Earth Surface, 123(10), 2677-2694. https://doi.org/10.1029/2018JF004611

Zlotnik, V. A. (2004). A concept of maximum stream depletion rate for leaky aquifers in alluvial valleys. Water Resources Research, 40(6). https://doi.org/10.1029/2003WR002932

Zlotnik, V. A., \& Tartakovsky, D. M. (2008). Stream Depletion by Groundwater Pumping in Leaky Aquifers. Journal of Hydrologic Engineering, 13(2), 43-50. https://doi.org/10.1061/(ASCE)10840699(2008)13:2(43)

Zorn, T. G., Seelbach, P. W., \& Rutherford, E. S. (2012). A Regional-Scale Habitat Suitability Model to Assess the Effects of Flow Reduction on Fish Assemblages in Michigan Streams. JAWRA Journal of the American Water Resources Association, 48(5), 871-895. https://doi.org/10.1111/j.17521688.2012.00656.x 


\section{Tables and Figures}

Table 1. Symbols/abbreviations, definitions, and units used in manuscript ( $\mathrm{L}=$ length, $\mathrm{T}=$ time)

\begin{tabular}{|c|c|c|}
\hline Symbol & Definition & Units \\
\hline$a$ & Area of a Thiessen polygon used for depletion apportionment & $\mathrm{L}^{2}$ \\
\hline$b$ & Aquifer thickness & $\mathrm{L}$ \\
\hline$b_{r}$ & Thickness of streambed clogging layer & $\mathrm{L}$ \\
\hline$C V$ & Coefficient of variation & - \\
\hline$d$ & Distance from a well to a point on a stream segment & $\mathrm{L}$ \\
\hline$f$ & $\begin{array}{l}\text { Fraction of total streamflow depletion from a well apportioned to a stream segment } \\
\text { (defined in Eq. 2-4) }\end{array}$ & - \\
\hline$K_{h}$ & Aquifer horizontal hydraulic conductivity & $\mathrm{L} \mathrm{T}^{-1}$ \\
\hline$K_{v}$ & Aquifer vertical hydraulic conductivity & $\mathrm{L} \mathrm{T}^{-1}$ \\
\hline$K_{r}$ & Hydraulic conductivity of streambed clogging layer & $\mathrm{L} \mathrm{T}^{-1}$ \\
\hline$K G E$ & Kling-Gupta Efficiency (defined in Eq. 8) & - \\
\hline$M A E$ & Mean Absolute Error & varies \\
\hline$M S E_{T}$ & Total Mean Squared Error & varies \\
\hline $\begin{array}{l}M S E_{C} \\
M S E_{V} \\
M S E_{B}\end{array}$ & $\begin{array}{l}\text { Proportion of } M S E_{T} \text { caused by correlation, variability, and bias (defined in Eq. 11- } \\
\text { 13) }\end{array}$ & - \\
\hline$n$ & Number of stream segments meeting stream proximity criteria & - \\
\hline$P$ & $\begin{array}{l}\text { Total number of points into which a stream segment is divided in the web } \\
\text { depletion apportionment equation (Eq. } 4 \text { ) }\end{array}$ & - \\
\hline$r$ & Pearson correlation coefficient & - \\
\hline$Q a$ & $\begin{array}{l}\text { Volumetric streamflow depletion rate in a stream segment considered in isolation } \\
\text { (ignoring other segments) calculated using an analytical model (defined in Eq. 5-6) }\end{array}$ & $\mathrm{L}^{3} \mathrm{~T}^{-1}$ \\
\hline$Q d$ & $\begin{array}{l}\text { Depletion potential; volumetric streamflow depletion in a stream segment } \\
\text { normalized by the pumping rate }(Q w) \text { (defined in Eq. } 1)\end{array}$ & - \\
\hline$Q w$ & Pumping rate of a well & $\mathrm{L}^{3} \mathrm{~T}^{-1}$ \\
\hline$S$ & Storativity & - \\
\hline$S_{C}, S_{V}, S_{B}$ & Scaling factors for correlation, variability, and bias errors in KGE calculation & - \\
\hline$T$ & Transmissivity & $\mathrm{L}^{2} \mathrm{~T}^{-1}$ \\
\hline$w$ & $\begin{array}{l}\text { Weighting factor used in inverse distance and web depletion apportionment } \\
\text { equations (Eq. } 3 \text { and Eq. 4, respectively) }\end{array}$ & - \\
\hline$w_{r}$ & Width of a stream segment & $\mathrm{L}$ \\
\hline$\lambda$ & Streambed conductance (defined in Eq. 7) & $\mathrm{L}^{2} \mathrm{~T}^{-1}$ \\
\hline
\end{tabular}




\section{Overview of analytical depletion functions}

Which stream segments will a proposed well impact, and how much will each stream segment be depleted? Step 1: Select stream segments meeting proximity criteria

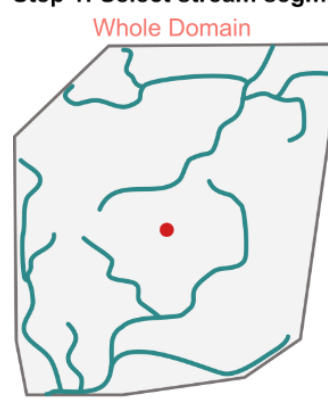

All stream segments included

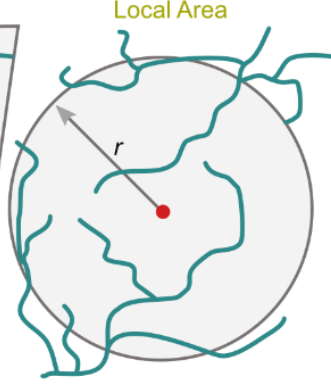

$r$ defined as $2 x$ max distance from any land point to any stream

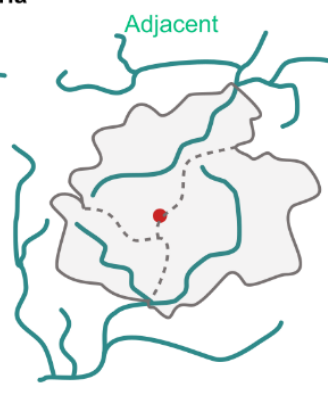

Catchments adjacent to well location

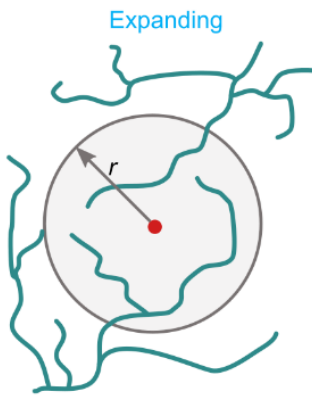

$r$ defined as max distance with depletion potential $\geq 1 \%$ at each timestep

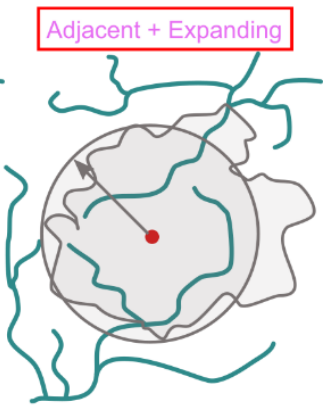

Any segment included in Adjacent or Expanding

Step 2: Use depletion apportionment equations to estimate the fraction of total depletion apportioned to each stream segment $\left(f_{i}\right)$

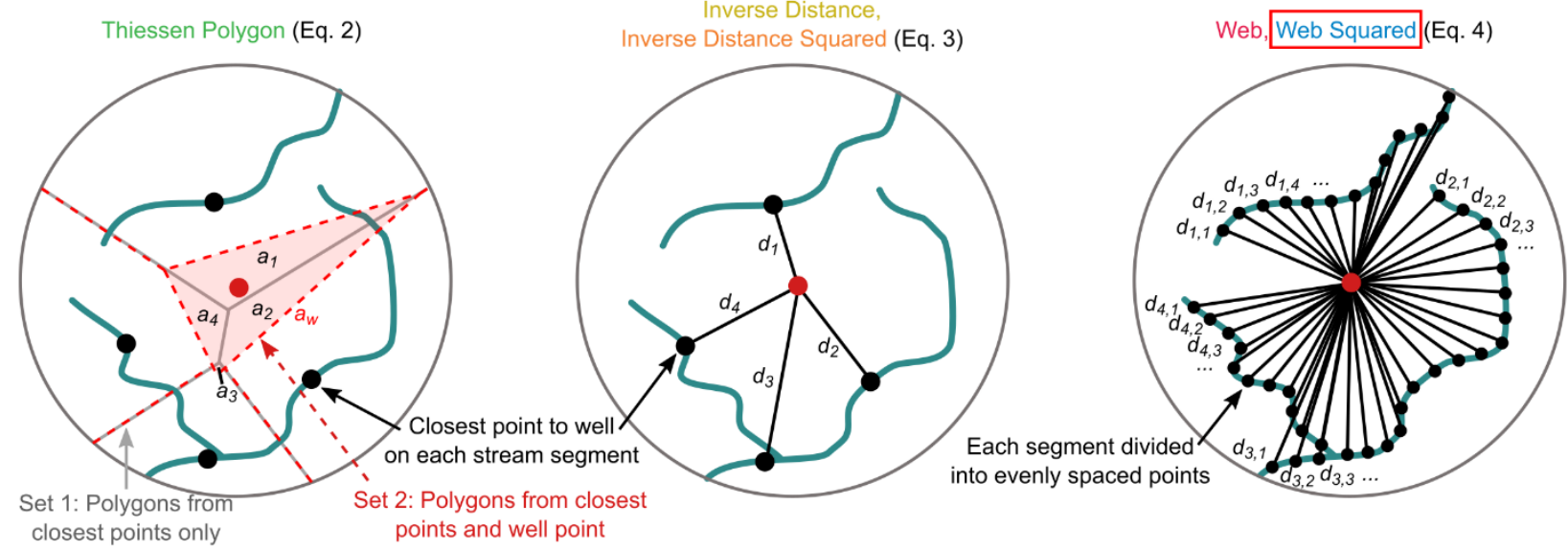

Step 3: Calculate streamflow depletion rate $(Q f)$ for each segment using analytical model

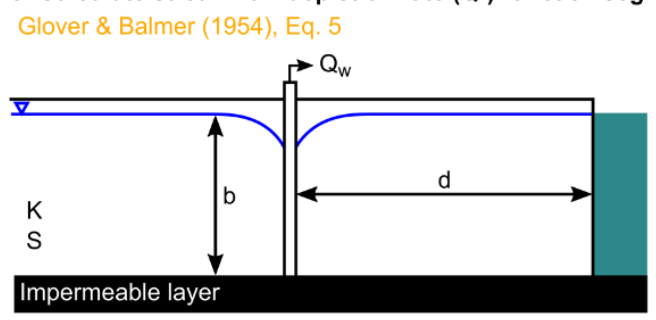

OR Hunt (1999), Eq. 6

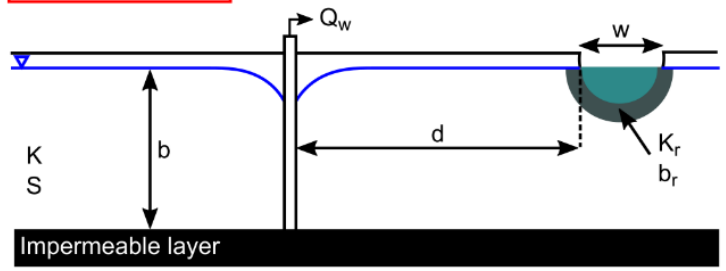

Step 4: Calculate the depletion potential for each stream segment as the product of Steps 2 and 3 using Eq. 1.

Figure 1. Diagram showing components of an analytical depletion function for a sample stream network. For each step, the option boxed in red is the option with the best overall performance (Section 4.2). Colors in component labels correspond to color-coding in Results plots. 


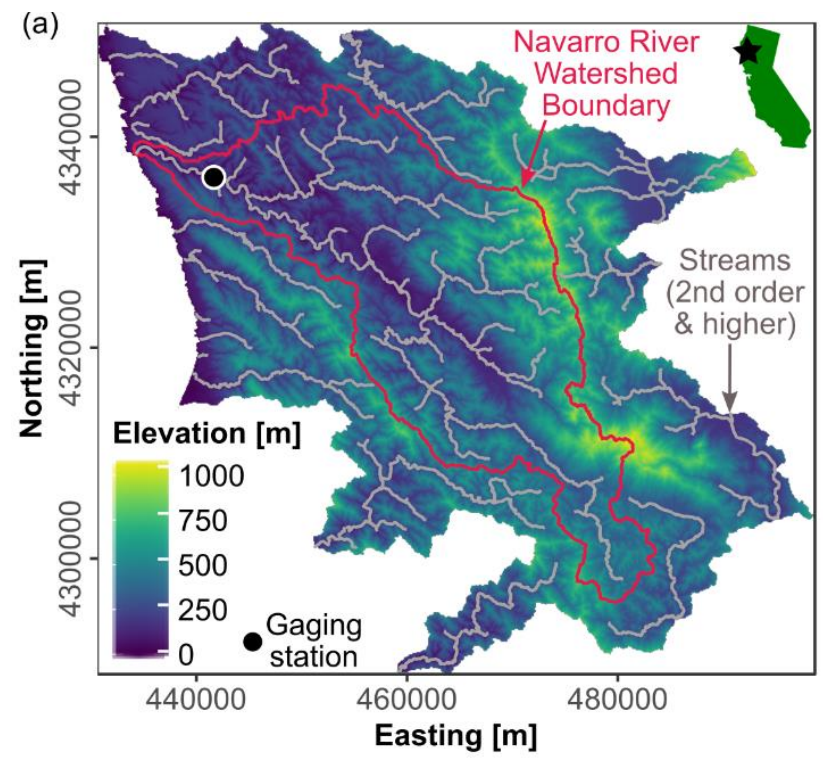

(c)

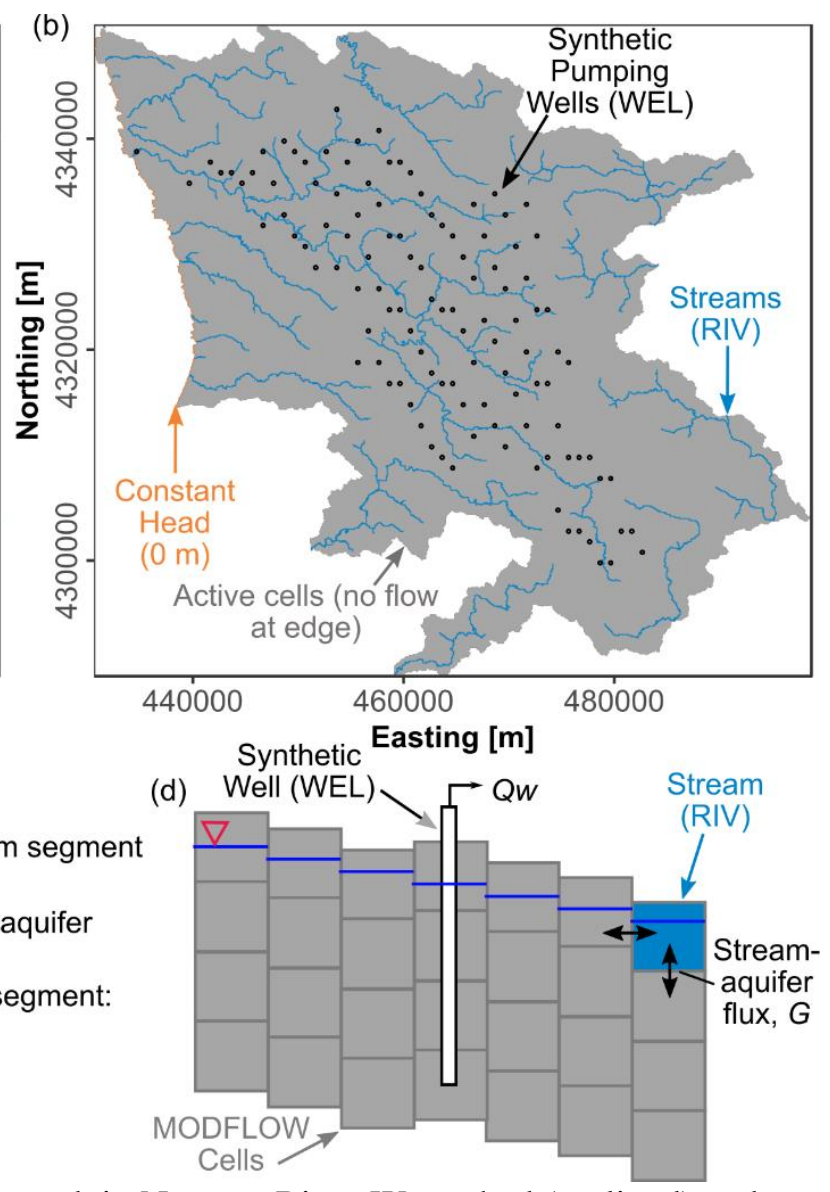

Figure 2. Study domain. (a) Elevation and stream network in Navarro River Watershed (outlined) and adjacent HUC12 watersheds. The star on the inset map shows the location of the domain within California. (b) Model domain and boundary conditions for MODFLOW model. Recharge is applied as a boundary condition to all active cells in top model layer. (c) Steps to calculate depletion potential using numerical model (based on Barlow \& Leake, 2012; different from steps shown in Figure 1 for analytical depletion functions); and (d) simplified representation of key processes in MODFLOW domain. 
(a) MODFLOW

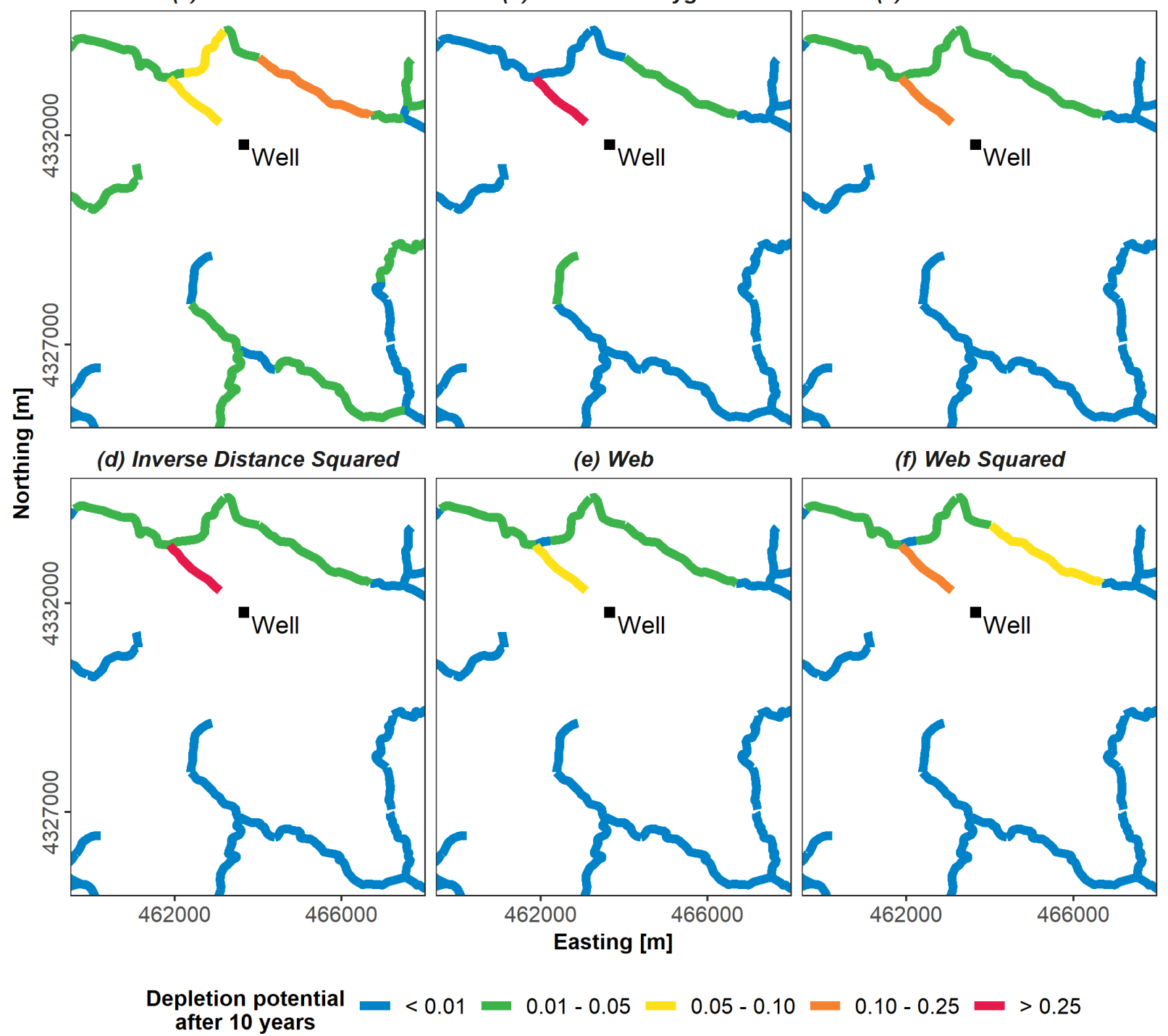

Figure 3. Example of the predicted distribution of depletion from a well after 10 years of pumping from (a) MODFLOW and (b-f) each of the depletion apportionment equations, combined with the Hunt analytical model and adjacent + expanding stream proximity criteria. The timeseries of depletion associated with this well is shown in Figure S7 ('Near' well). 

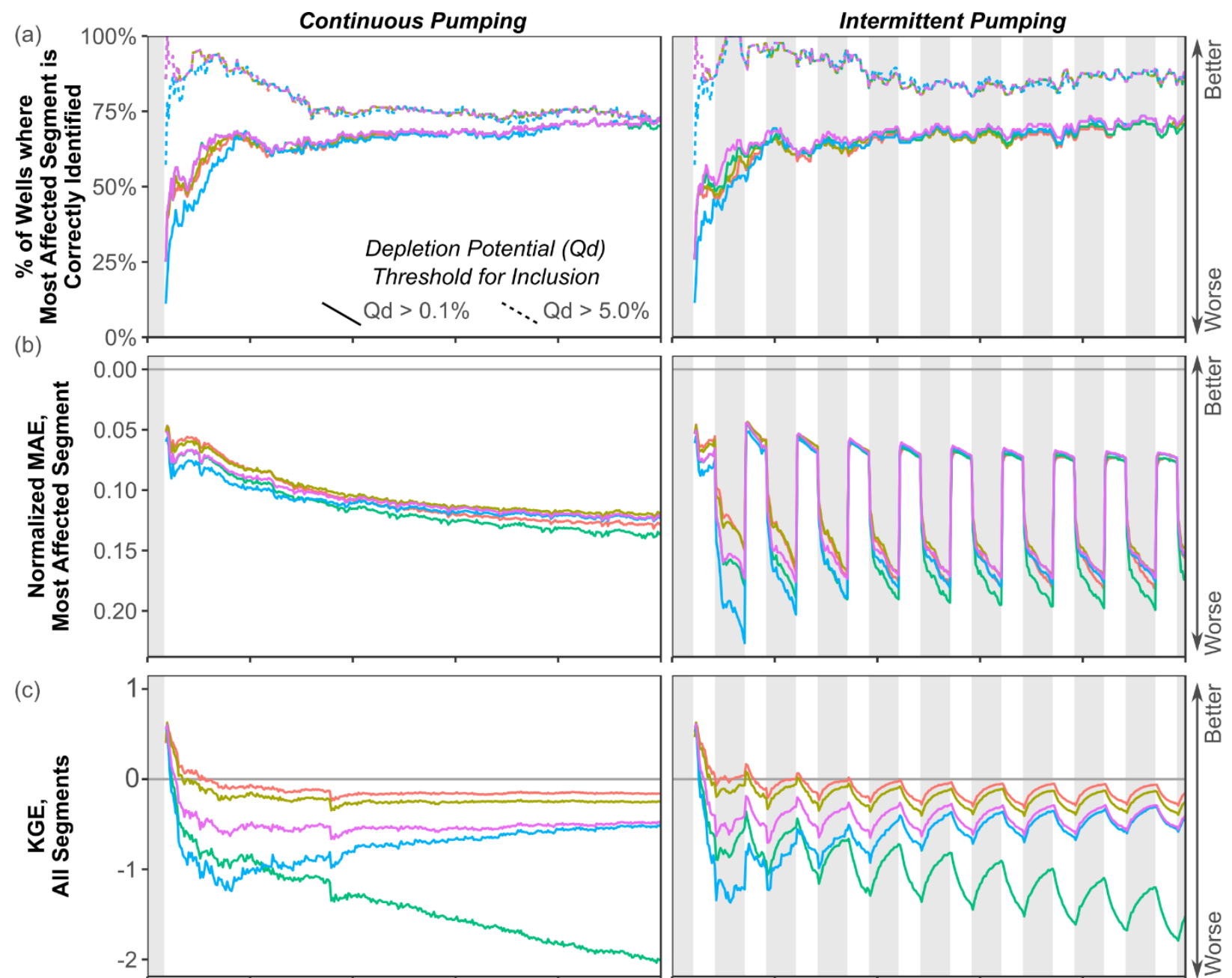

(d)
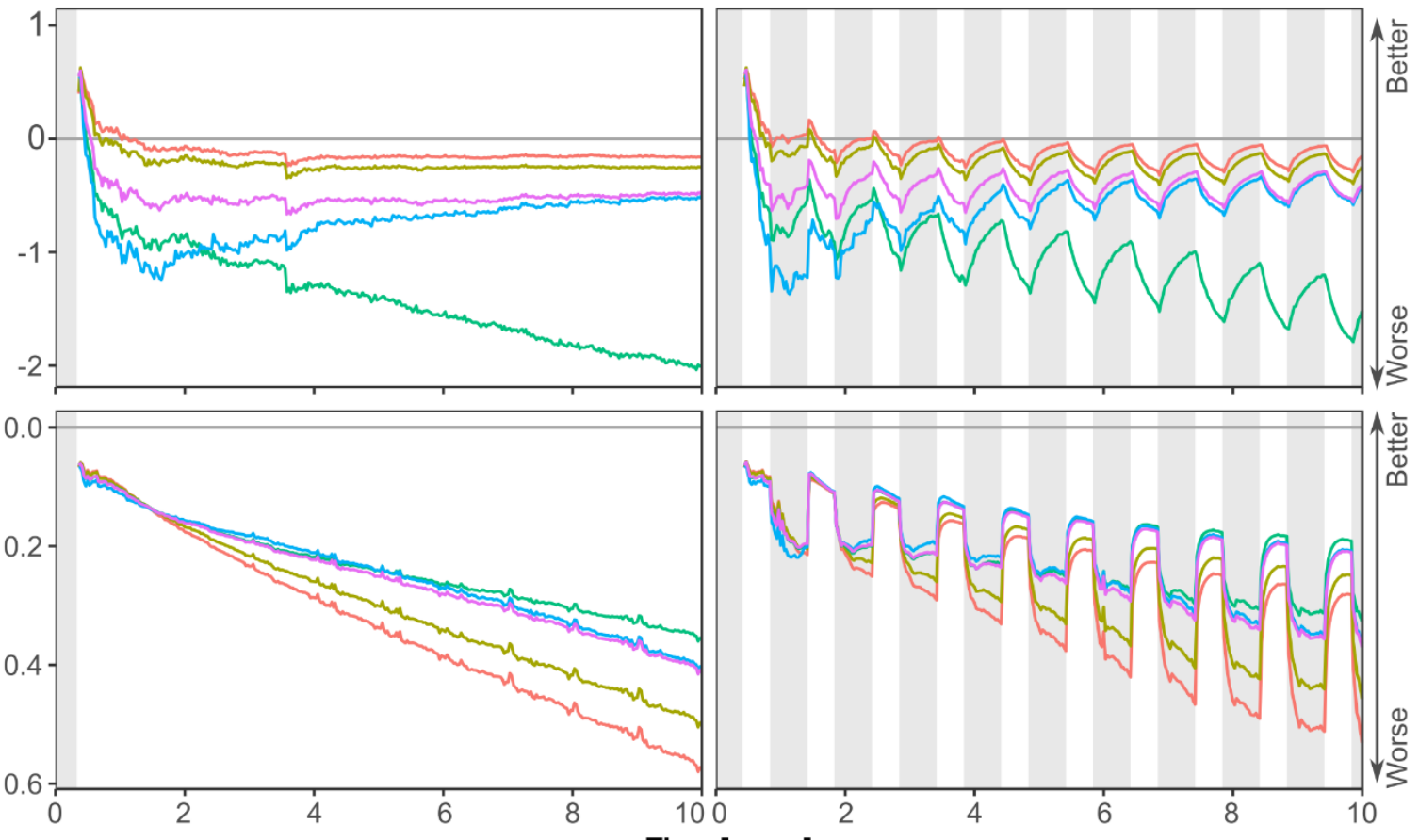

Web squared, Hunt, and stream proximity criteria

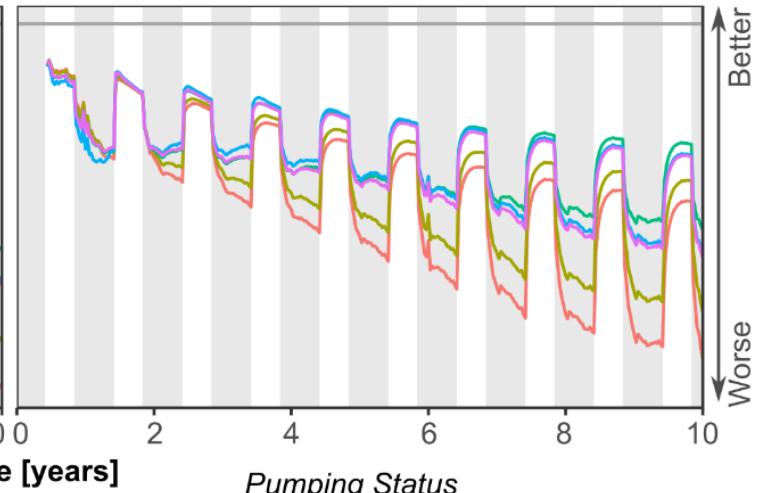

$$
\begin{aligned}
& \text { Whole Domain } \backslash \text { Local Area } \backslash \text { Adjacent } \\
& \text { Expanding } \\
& \text { Adjacent }+ \text { Expanding }
\end{aligned}
$$

Figure 4. Comparison across stream proximity criteria for each performance metric. (a) Spatial distribution of primary impact; (b) magnitude of primary impact; (c) spatial distribution of overall impacts; (d) magnitude of overall impacts. Note that y-axis is reversed on (b) and (d) so that upwards indicates better performance. Left column shows continuous pumping experiment and right column is intermittent pumping experiment. Results shown are for Hunt analytical model and web squared depletion apportionment equation compared to MODFLOW model using RIV for stream features. 

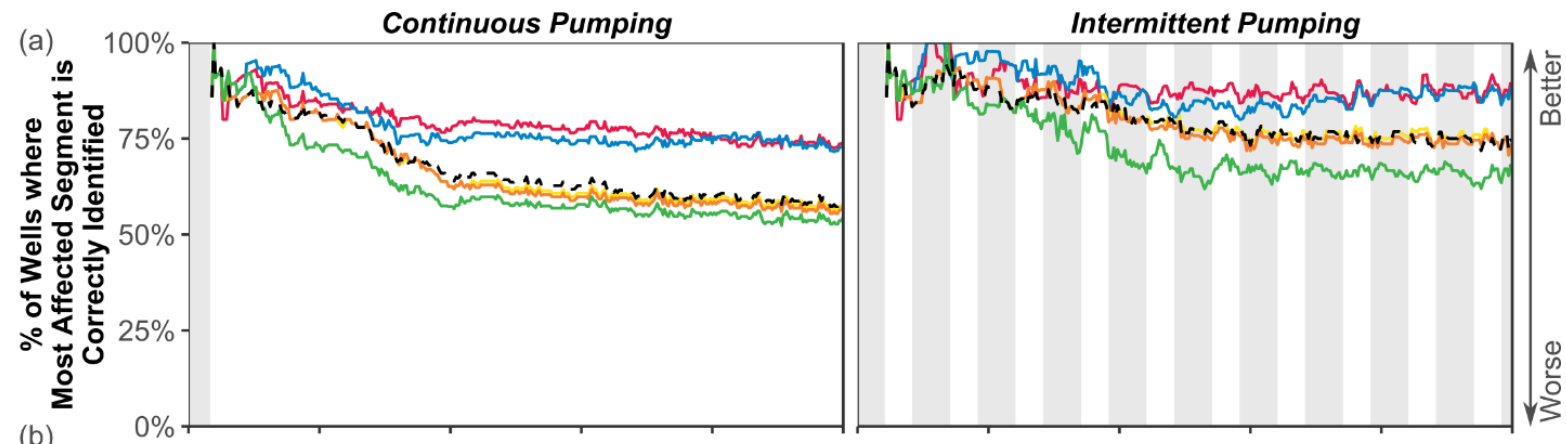

(b)
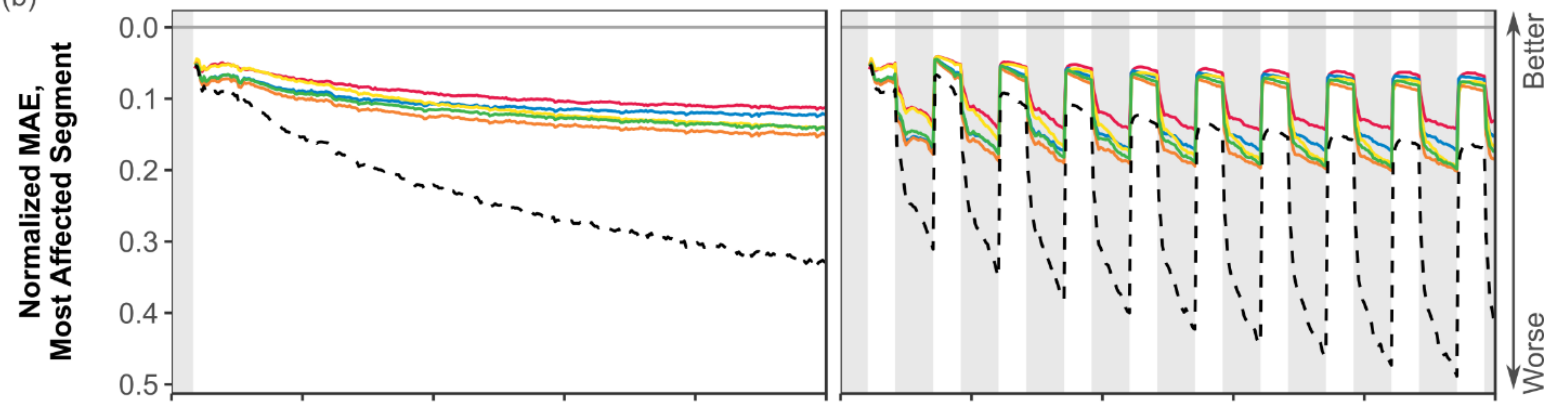

(c)
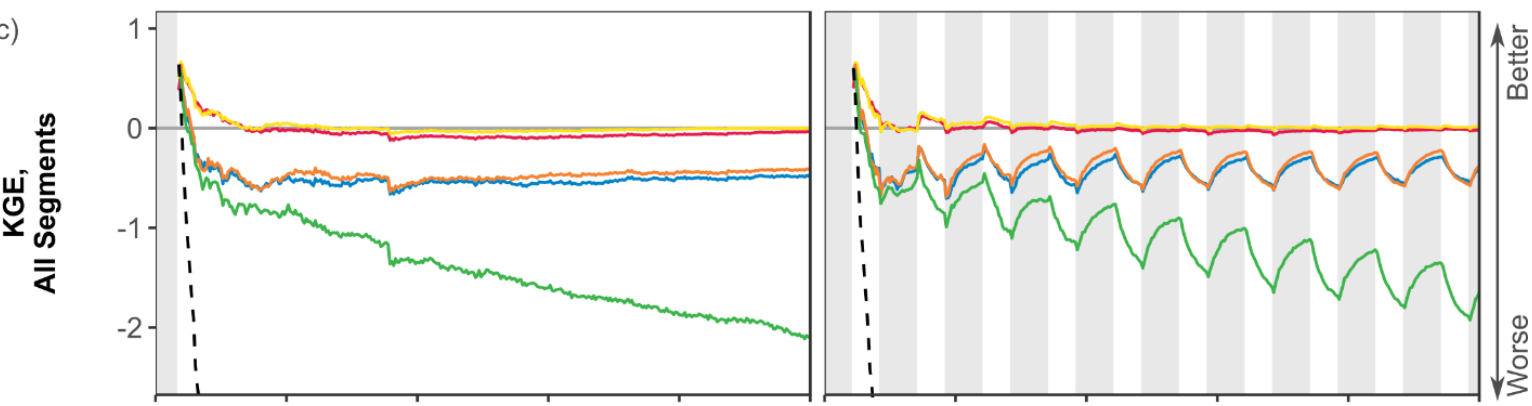

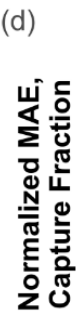
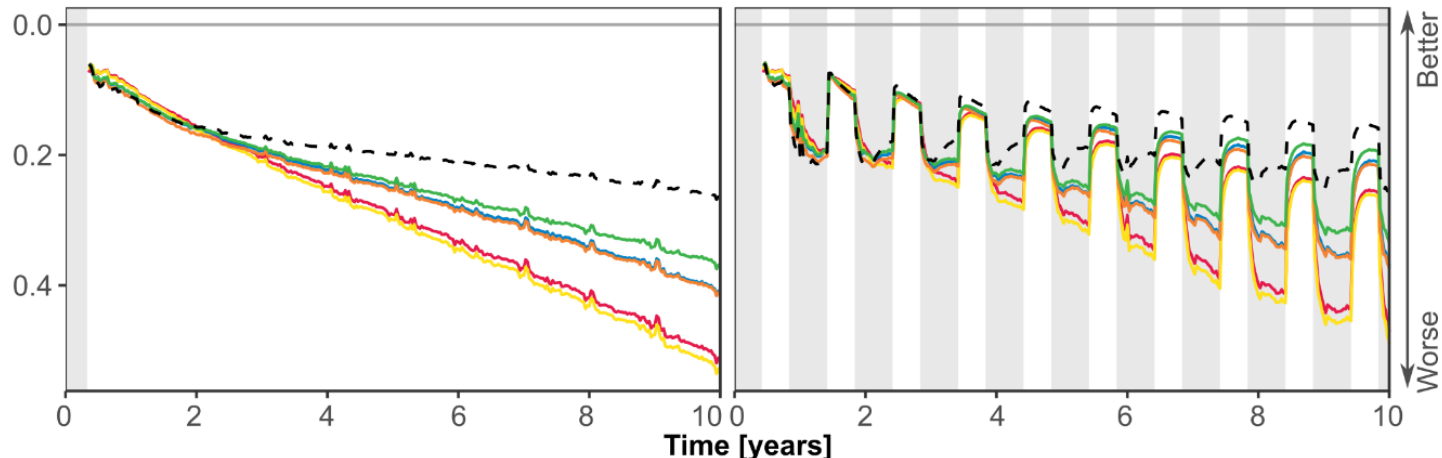

Adjacent + expanding, Hunt, and depletion apportionment equation

Pumping Status

$\checkmark$ Web

Inverse Distance

Thiessen Polygon

$\square$ On $\square$ Off

Web Squared Inverse Distance Squared $\because$. No Apportionment

Figure 5. Comparison across depletion apportionment equations for each performance metric. (a) Spatial distribution of primary impact for segments with depletion potential > 5\%; (b) magnitude of primary impact; (c) spatial distribution of overall impacts; (d) magnitude of overall impacts. The "No Apportionment' line shows the performance of the Hunt analytical model without considering stream proximity criteria or depletion apportionment equations. Left column shows continuous pumping experiment and right column is intermittent pumping experiment. Results shown are for Hunt analytical model and adjacent + expanding stream proximity criteria compared to MODFLOW model using RIV for stream features. 

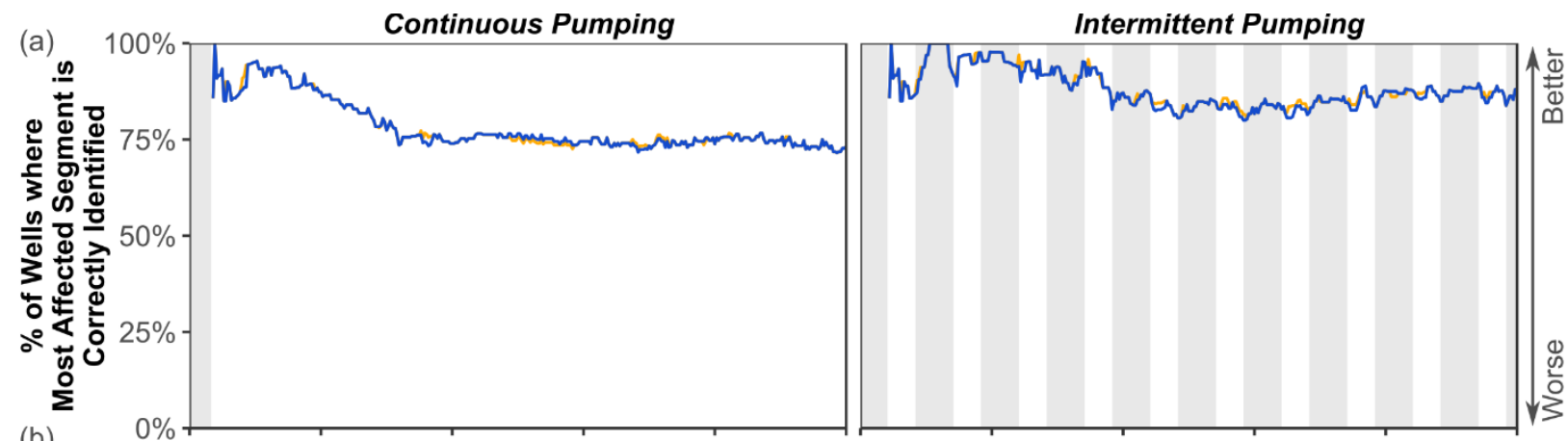

(b)
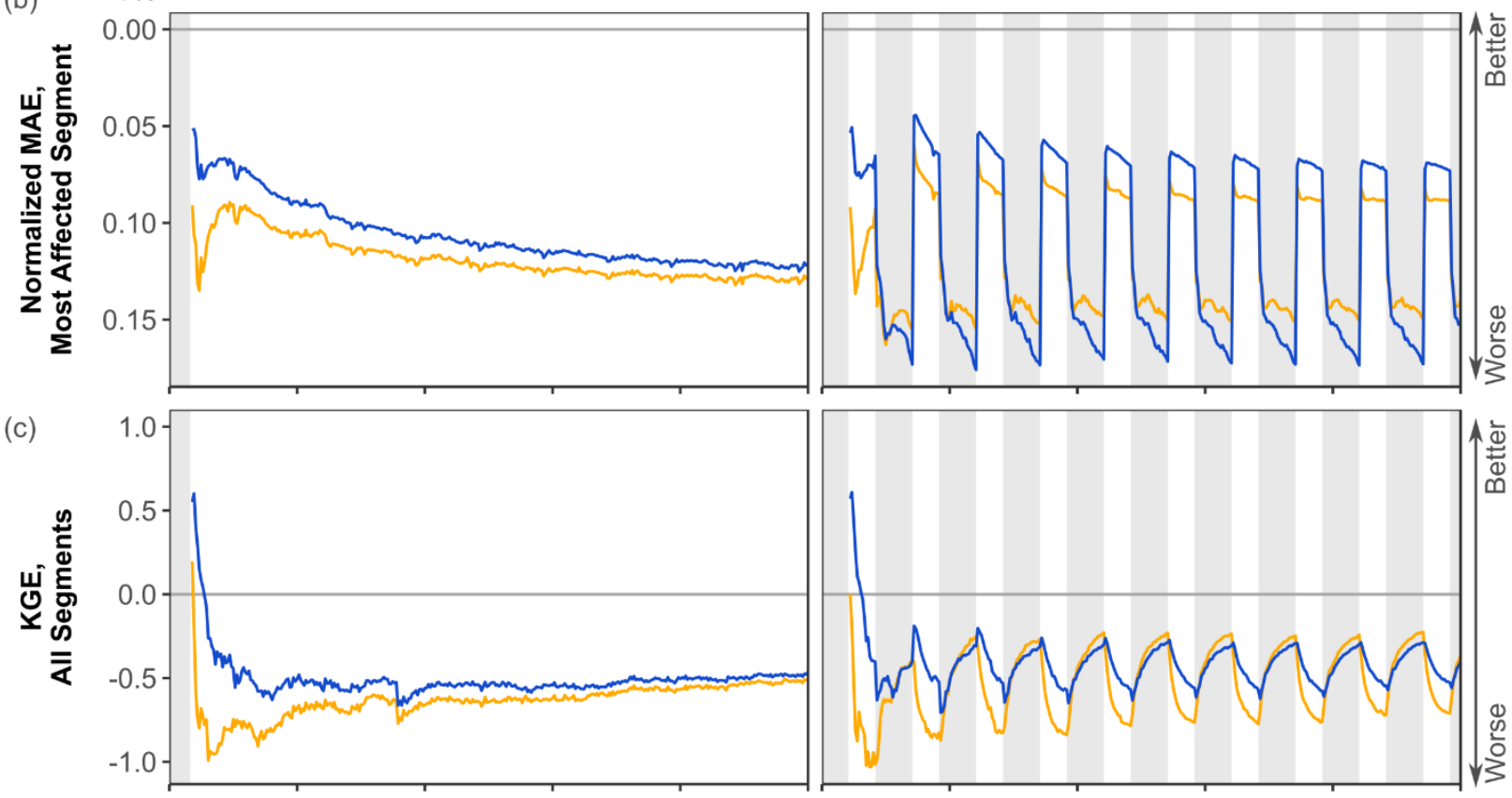

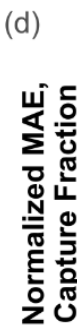
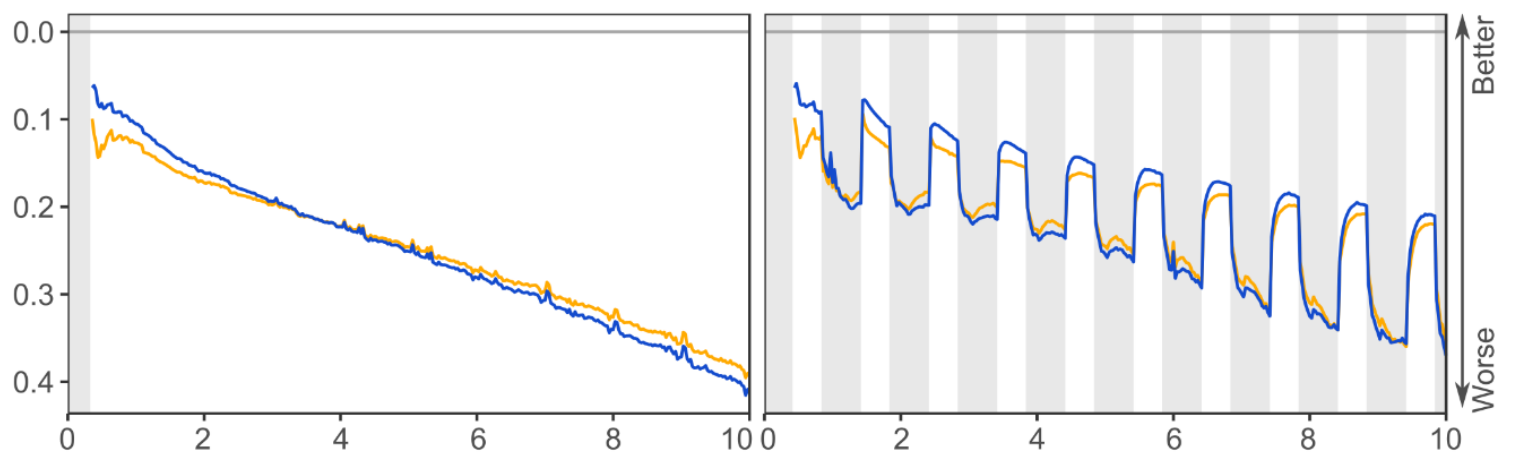

Adjacent + expanding, web squared, and analytical model

Pumping Status

$\checkmark$ Glover \Hunt $\square$ On $\square$ off

Figure 6. Comparison across analytical models for each performance metric. (a) Spatial distribution of primary impact; (b) magnitude of primary impact; (c) spatial distribution of overall impacts; (d) magnitude of overall impacts. Note that y-axis is reversed on (b) and (d) so that upwards indicates better performance. Left column shows continuous pumping experiment and right column is intermittent pumping experiment. Results shown are for adjacent + expanding stream proximity criteria and web squared depletion apportionment equation compared to MODFLOW model using RIV for stream features. 

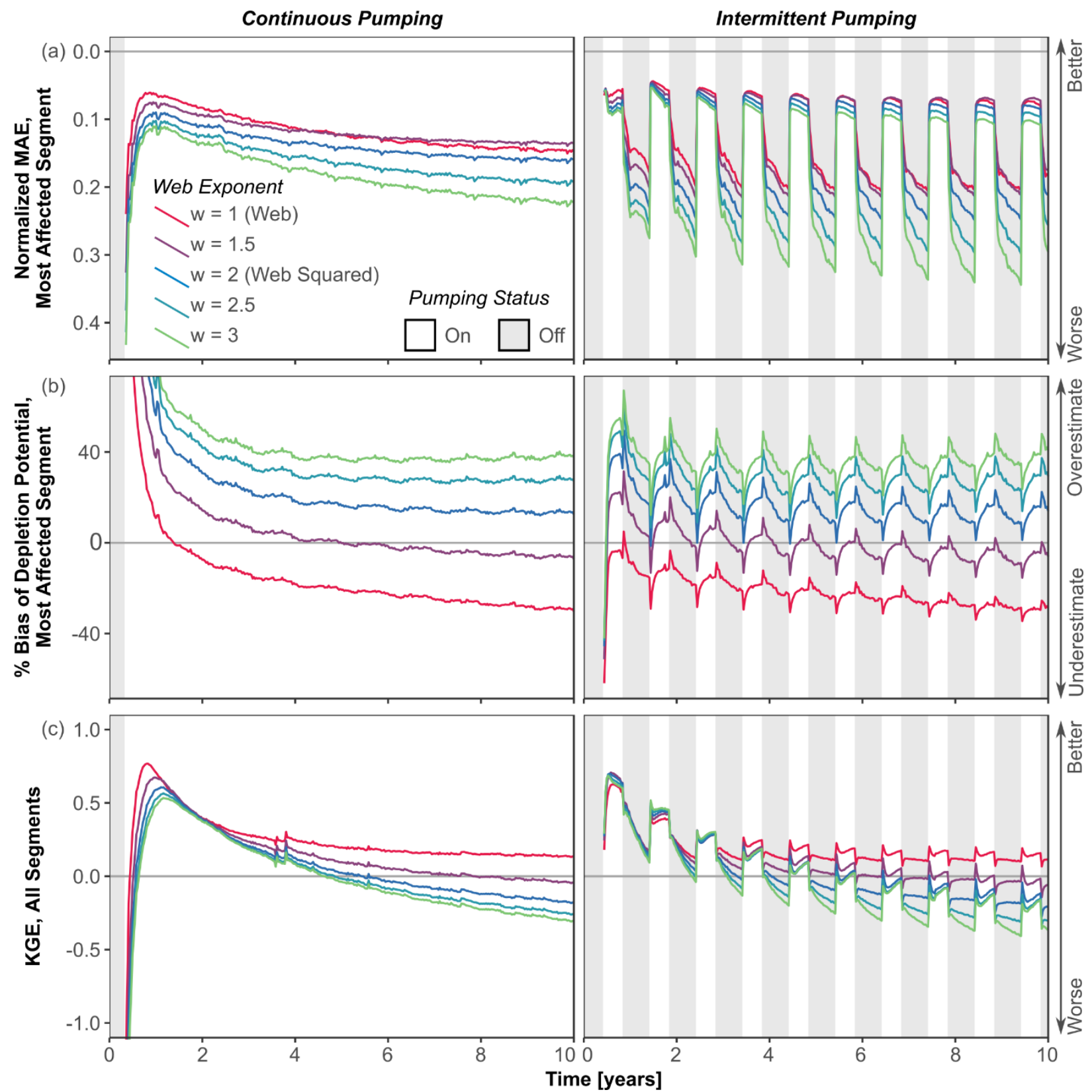

Figure 7. Comparison among different exponents for web depletion apportionment equation. (a) Magnitude of primary impact; (b) bias of primary impact, where a positive bias means that the analytical depletion function overestimates depletion relative to the MODFLOW model; (c) magnitude of overall impacts. Note that y-axis in (a) is reversed so that upwards indicates better performance. Left column shows continuous pumping experiment and right column is intermittent pumping experiment. Results shown are for adjacent + expanding stream proximity criteria and Hunt model compared to MODFLOW model using RIV for stream features. 

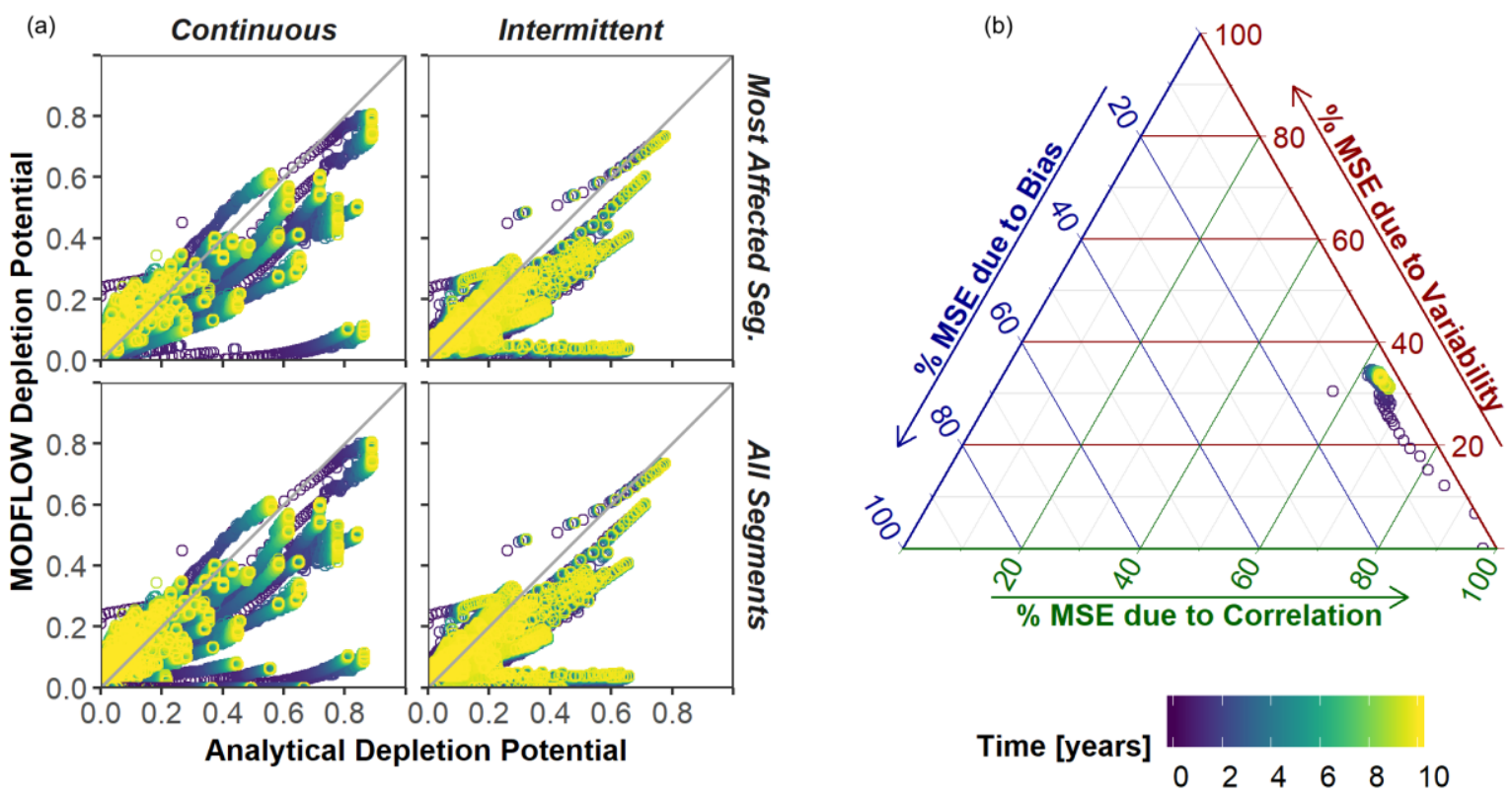

Figure 8. (a) Comparison between MODFLOW and analytical predicted depletion function for (top row) the most affected segment and (bottom row) all segments for the (left column) continuous and (right column) intermittent pumping experiments. The gray line in each plot shows a 1:1 match. (b) Relative contribution of variability, bias, and correlation to overall mean squared error (MSE) through time for the most affected segment in the continuous pumped experiment; all segments and intermittent pumping experiment are shown in Figure S11. In both plots, the best-performing analytical depletion function is compared to the MODFLOW model using RIV for stream features. 
(a)

$\underset{\text { MAE }}{\text { Normalized }} \bigcirc 0.1 \bigcirc 0.2 \bigcirc 0.3 \bigcirc 0.4$
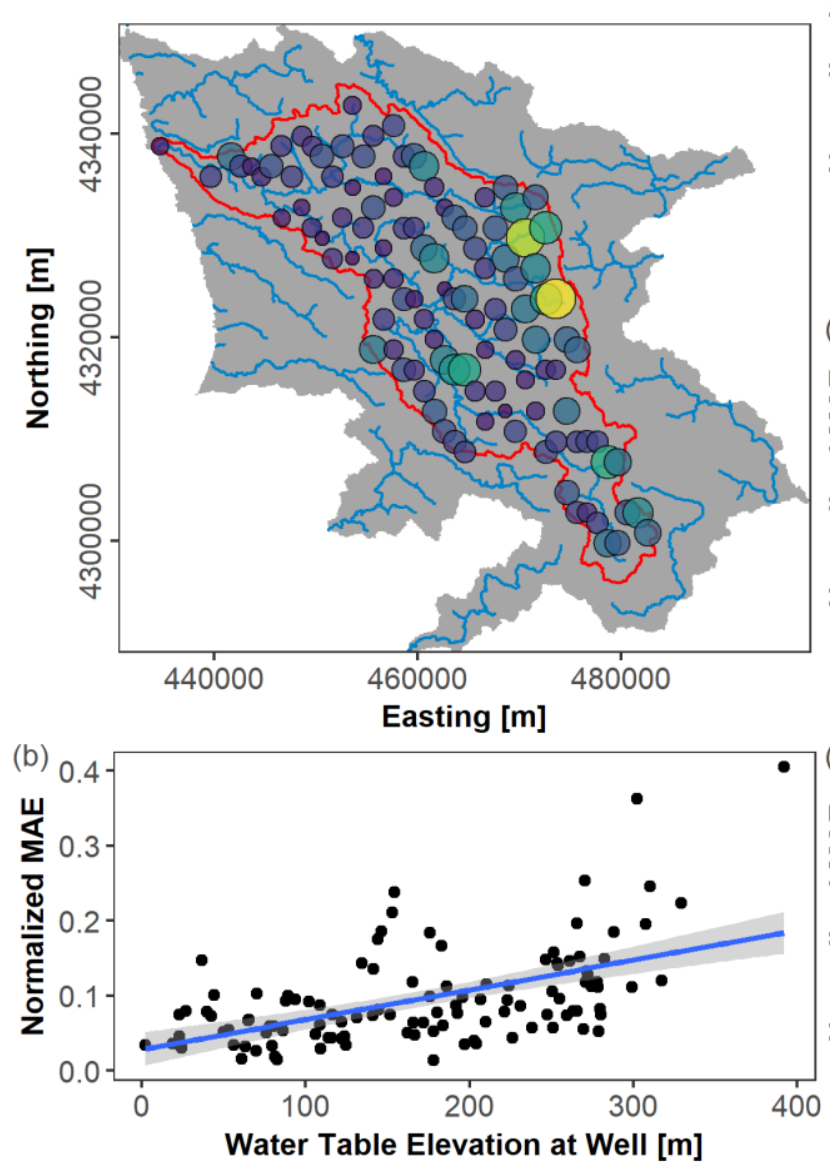
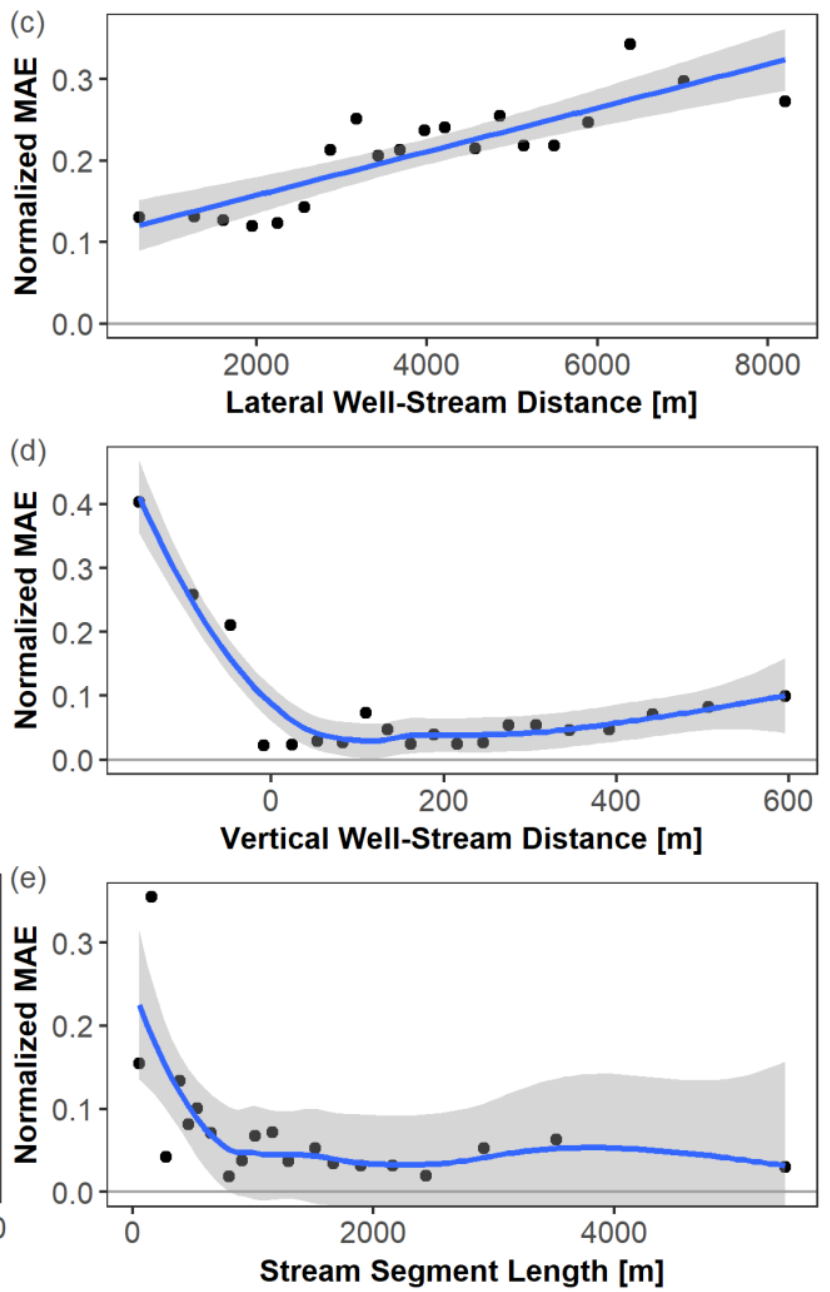

Figure 9. Normalized MAE during the final year of the continuous pumping experiment for each well, shown by (a) position within domain, with the MODFLOW domain colored gray and streams colored blue; (b) steady-state water table elevation; (c) lateral distance between well and stream segment; (d) vertical distance between well and stream segment, where a negative value means the well is at a lower elevation than the stream; and (e) stream segment length. For each plot, the variable on the $\mathrm{x}$-axis was divided into 20 quantiles used to calculate normalized MAE. Blue lines in (b) and (c) are linear best-fit $\left(\mathrm{R}^{2}=0.29\right.$ and $\mathrm{R}^{2}=0.72$, respectively; $\mathrm{p}<10^{-5}$ for both), and blue lines in (d) and (e) are smoothed loess filters. MODFLOW model with RIV stream features used for evaluation; see Figure S12 for comparison with MODFLOW SFR model. 


\section{Supplementary Information}

Table S1. Comparison of streamflow depletion modeling approaches (from Zipper et al., 2018a).

\begin{tabular}{|l|l|l|l|}
\hline & $\begin{array}{l}\text { Analytical models with } \\
\text { depletion apportionment } \\
\text { equations }\end{array}$ & $\begin{array}{l}\text { Archetypal numerical } \\
\text { models }\end{array}$ & $\begin{array}{l}\text { Site-specific numerical } \\
\text { models }\end{array}$ \\
\hline $\begin{array}{l}\text { Boundary } \\
\text { conditions }\end{array}$ & $\begin{array}{l}\text { Analytical models consider } \\
\text { one or two streams with } \\
\text { simplified geometry and } \\
\text { constant head; depletion } \\
\text { apportionment equations } \\
\text { distribute depletion to } \\
\text { different stream reaches. }\end{array}$ & $\begin{array}{l}\text { Complex stream geometry } \\
\text { simulated as constant river } \\
\text { boundary condition with } \\
\text { specified head. }\end{array}$ & $\begin{array}{l}\text { Complex stream geometry } \\
\text { represented by a mix of } \\
\text { boundary conditions such as } \\
\text { river, constant head, drain } \\
\text { etc. }\end{array}$ \\
\hline $\begin{array}{l}\text { Parameter } \\
\text { values, } \\
\text { input data } \\
\text { and } \\
\text { geometry }\end{array}$ & $\begin{array}{l}\text { Assume flat, infinite } \\
\text { homogeneous, isotropic } \\
\text { aquifers with no vertical } \\
\text { flow. Input datasets exist for } \\
\text { most aquifers. }\end{array}$ & $\begin{array}{l}\text { Simplified subsurface; } \\
\text { topographic relief can be } \\
\text { included. Moderate input } \\
\text { data requirements which } \\
\text { exist for most aquifers. }\end{array}$ & $\begin{array}{l}\text { Heterogeneous and } \\
\text { anisotropic, multiple layers } \\
\text { with complex geometry. } \\
\text { Many regions do not have } \\
\text { enough data. }\end{array}$ \\
\hline $\begin{array}{l}\text { Required } \\
\text { effort, } \\
\text { skill and } \\
\text { calibration }\end{array}$ & $\begin{array}{l}\text { Moderate effort (minutes - } \\
\text { days) and skill (generalists). } \\
\text { Not calibrated. }\end{array}$ & $\begin{array}{l}\text { Significant effort (weeks) } \\
\text { and skill (specialists). Not } \\
\text { calibrated. }\end{array}$ & $\begin{array}{l}\text { Significant effort (months) } \\
\text { and skill (experts). } \\
\text { Calibrated to hydrogeologic } \\
\text { and hydrologic } \\
\text { measurements. }\end{array}$ \\
\hline $\begin{array}{l}\text { Examples } \\
\text { from } \\
\text { literature }\end{array}$ & $\begin{array}{l}\text { Foglia et al., 2013; Jayawan } \\
\text { et al., 2016; Reeves et al., } \\
\text { 2009. Only Reeves tested } \\
\text { depletion apportionment } \\
\text { equations. }\end{array}$ & $\begin{array}{l}\text { Kendy \& Bredehoeft, } \\
\text { 2006; Konikow \& Leake, } \\
\text { 2014; Lackey et al., 2015. }\end{array}$ & $\begin{array}{l}\text { Ahlfeld et al., 2016; } \\
\text { Feinstein et al., 2016; } \\
\text { Fienen et al., 2018; Reeves } \\
\text { et al., 2009. }\end{array}$ \\
\hline
\end{tabular}


Table S2. Performance metrics averaged over entire 10-year simulation period for selected analytical depletion functions. Italicized values shows the best-performing analytical depletion function assessed in Section 4.2. Bolded values show the best performance for that criteria (separately for transient and intermittent pumping scenarios).

\begin{tabular}{|c|c|c|c|c|c|c|c|}
\hline & & & & $\begin{array}{l}\text { Spatial } \\
\text { distribution of } \\
\text { primary impact }\end{array}$ & $\begin{array}{l}\text { Magnitude of } \\
\text { primary impact }\end{array}$ & $\begin{array}{l}\text { Spatial } \\
\text { distribution of } \\
\text { overall impacts }\end{array}$ & $\begin{array}{l}\text { Magnitude of } \\
\text { overall impacts }\end{array}$ \\
\hline $\begin{array}{l}\text { Pumping } \\
\text { Schedule }\end{array}$ & $\begin{array}{l}\text { Stream Proximity } \\
\text { Criteria }\end{array}$ & $\begin{array}{l}\text { Depletion } \\
\text { Apportionment } \\
\text { Equation } \\
\end{array}$ & $\begin{array}{l}\text { Analytical } \\
\text { Model }\end{array}$ & $\begin{array}{l}\% \text { of wells where } \\
\text { most affected } \\
\text { segment is } \\
\text { correctly identified }\end{array}$ & $\begin{array}{l}\text { Normalized MAE, } \\
\text { most affected } \\
\text { segment }\end{array}$ & KGE, all segments & $\begin{array}{l}\text { Normalized MAE, } \\
\text { capture fraction }\end{array}$ \\
\hline Transient & Adjacent + expanding & Web squared & Hunt & $76.7 \%$ & 0.104 & -0.518 & 0.210 \\
\hline Transient & Whole domain & Web squared & Hunt & $76.6 \%$ & 0.105 & -0.149 & 0.279 \\
\hline Transient & Local area & Web squared & Hunt & $76.7 \%$ & 0.101 & -0.244 & 0.248 \\
\hline Transient & Adjacent & Web squared & Hunt & $76.7 \%$ & 0.112 & -1.632 & 0.196 \\
\hline Transient & Expanding & Web squared & Hunt & $76.2 \%$ & 0.108 & -0.632 & 0.204 \\
\hline Transient & Adjacent + expanding & Web & Hunt & $78.2 \%$ & 0.092 & -0.058 & 0.244 \\
\hline Transient & Adjacent + expanding & Inv. distance & Hunt & $64.4 \%$ & 0.107 & -0.004 & 0.252 \\
\hline Transient & Adjacent + expanding & Inv. dist. squared & Hunt & $63.8 \%$ & 0.123 & -0.457 & 0.213 \\
\hline Transient & Adjacent + expanding & Thiessen polygon & Hunt & $59.9 \%$ & 0.114 & -1.667 & 0.199 \\
\hline Transient & Adjacent + expanding & Web squared & Glover & $76.7 \%$ & 0.115 & -0.584 & 0.207 \\
\hline Intermittent & Adjacent + expanding & Web squared & Hunt & $87.0 \%$ & 0.053 & -0.420 & 0.120 \\
\hline Intermittent & Whole domain & Web squared & Hunt & $86.8 \%$ & 0.053 & -0.134 & 0.158 \\
\hline Intermittent & Local area & Web squared & Hunt & $86.8 \%$ & 0.052 & -0.221 & 0.142 \\
\hline Intermittent & Adjacent & Web squared & Hunt & $86.8 \%$ & 0.057 & -1.206 & 0.115 \\
\hline Intermittent & Expanding & Web squared & Hunt & $87.0 \%$ & 0.056 & -0.514 & 0.117 \\
\hline Intermittent & Adjacent + expanding & Web & Hunt & $87.7 \%$ & 0.045 & -0.003 & 0.137 \\
\hline Intermittent & Adjacent + expanding & Inv. distance & Hunt & $79.1 \%$ & 0.052 & 0.036 & 0.141 \\
\hline Intermittent & Adjacent + expanding & Inv. dist. squared & Hunt & $78.1 \%$ & 0.061 & -0.390 & 0.124 \\
\hline Intermittent & Adjacent + expanding & Thiessen polygon & Hunt & $70.4 \%$ & 0.057 & -1.282 & 0.115 \\
\hline Intermittent & Adjacent + expanding & Web squared & Glover & $87.3 \%$ & 0.059 & -0.489 & 0.125 \\
\hline
\end{tabular}




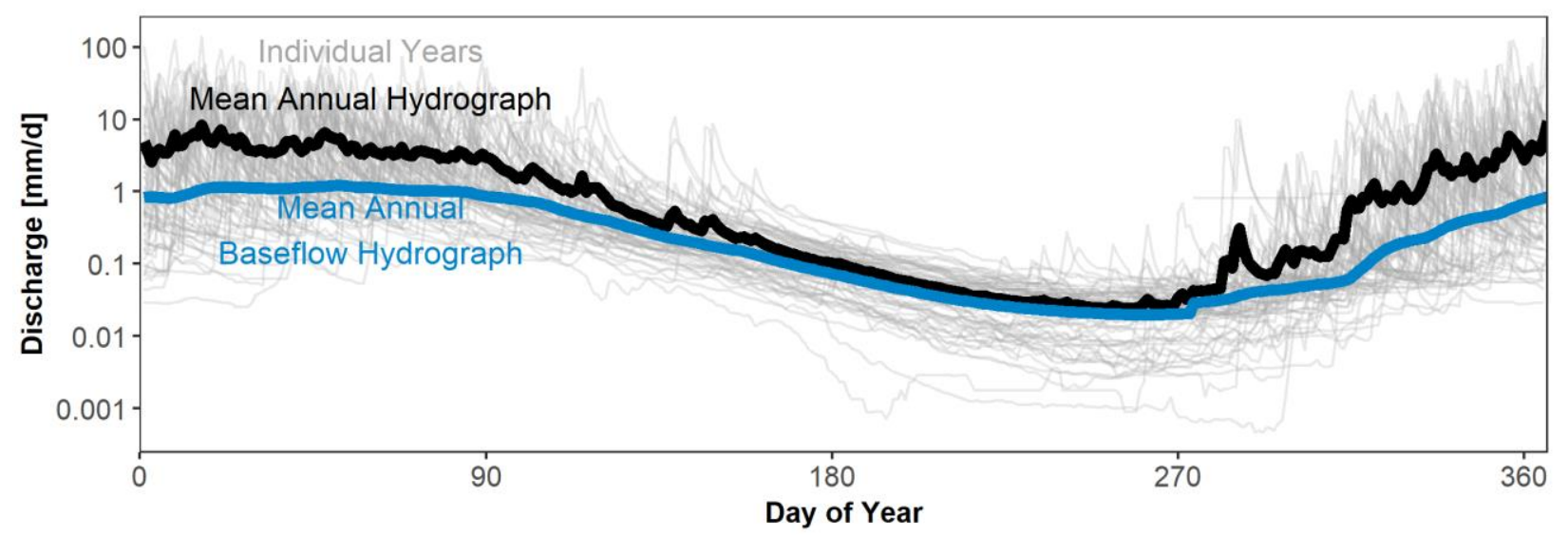

Figure S1. Streamflow in the Navarro River Watershed (USGS NWIS station \#11468000). Daily unit discharge for the 1951-2017 water years. Baseflow separated using recursive digital filter with exponent of 0.925 (Nathan \& McMahon, 1990).

(a) Precipitation $[\mathrm{mm} / \mathrm{mo}]$

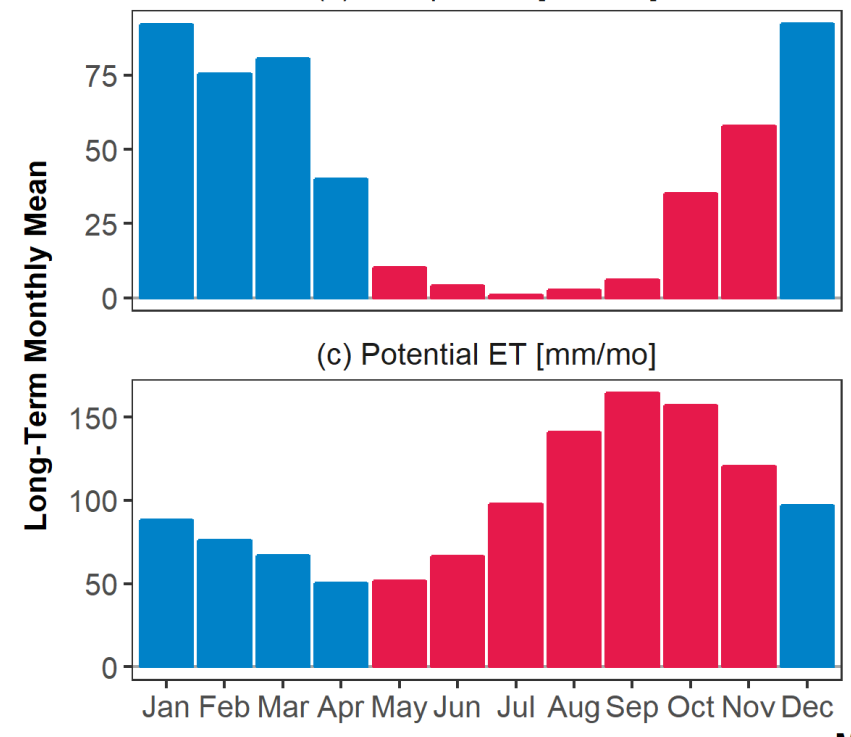

(b) Max Daily Temperature [C]

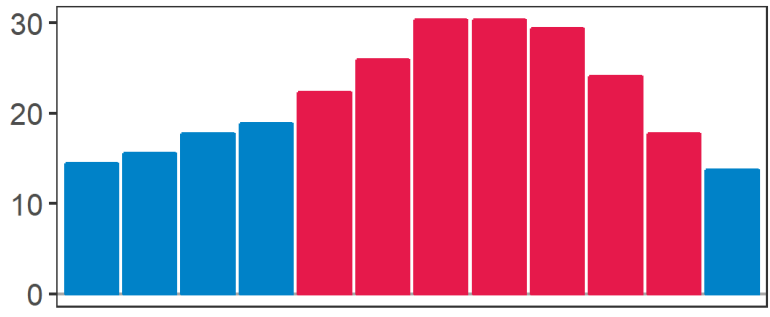

(d) Precip. Deficit (PET - Precip) $[\mathrm{mm} / \mathrm{mo}]$

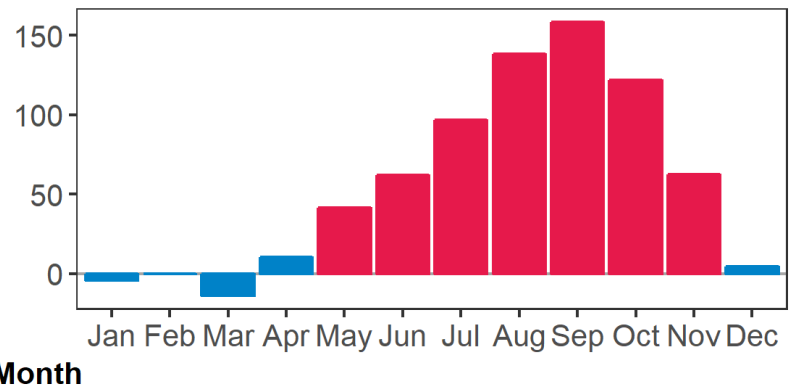

Figure S2. Long-term mean monthly (a) cumulative precipitation, (b) maximum daily air temperature, (c) potential evapotranspiration [PET] estimated using Hargreaves (1994) equation; and (d) precipitation deficit, calculated as monthly PET - precipitation. These data are used to distribute groundwater recharge into the 5 months constituting the wet season, which are shown in blue. 


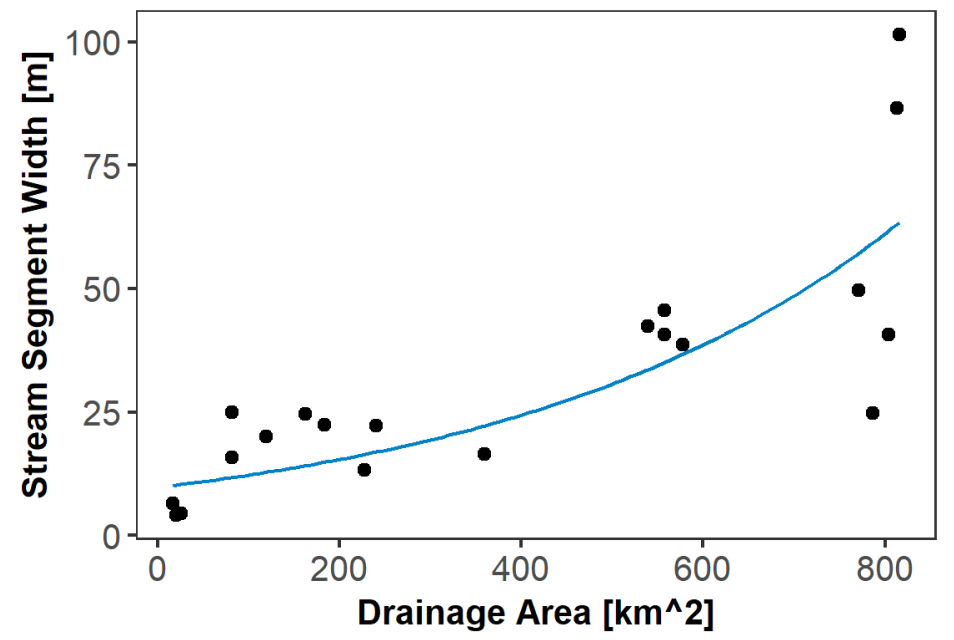

Figure S3. Function used to define stream segment width as a function of drainage area based on measurements from Google Earth imagery. Blue line is a best-fit function $\left(y=9.7133 \mathrm{e}^{0.0023 x} ; \mathrm{R}^{2}=0.67\right)$. The maximum possible stream segment width was capped at $100 \mathrm{~m}$ corresponding to measurements at the watershed outlet. 
RIV
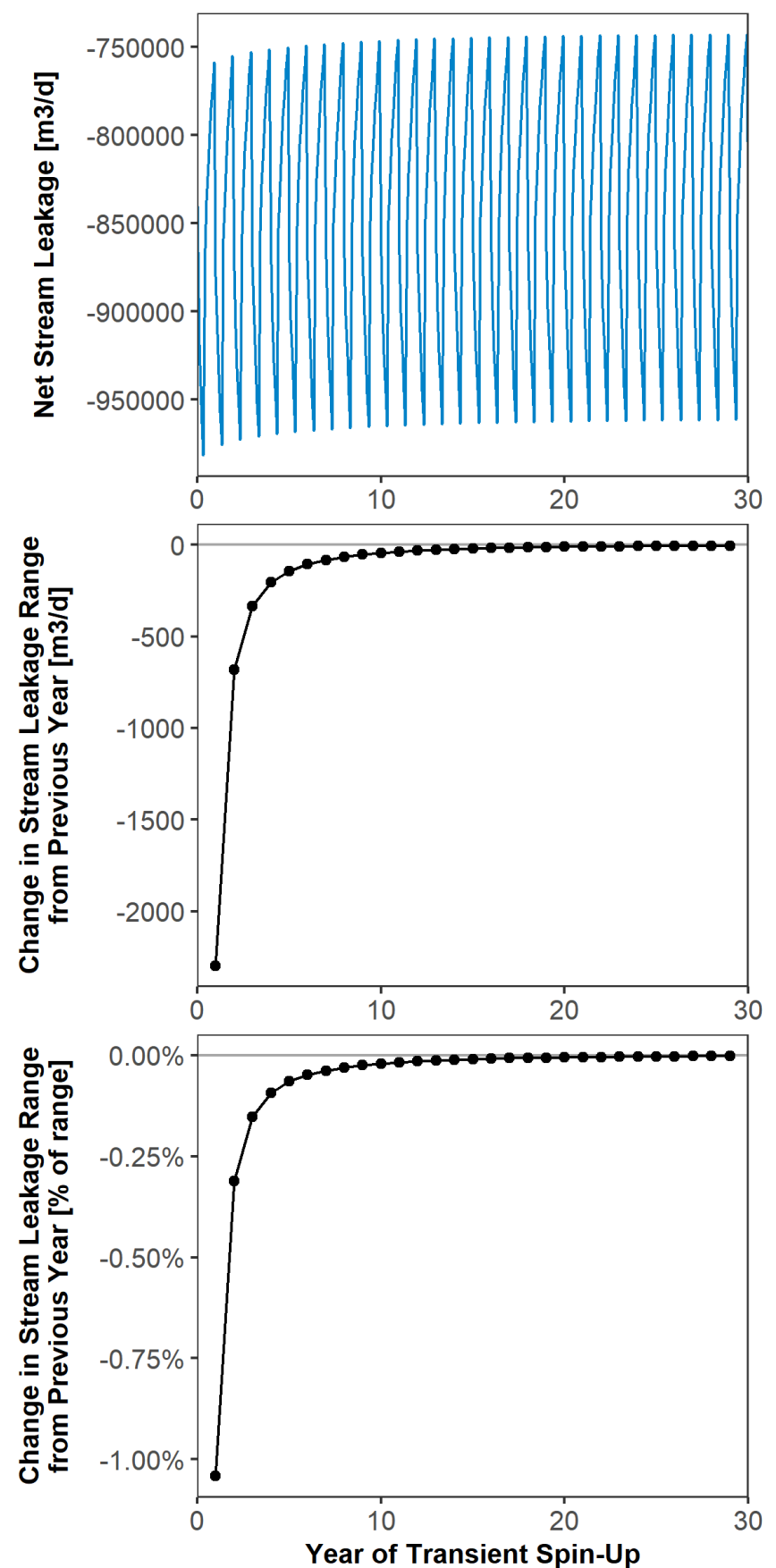

SFR
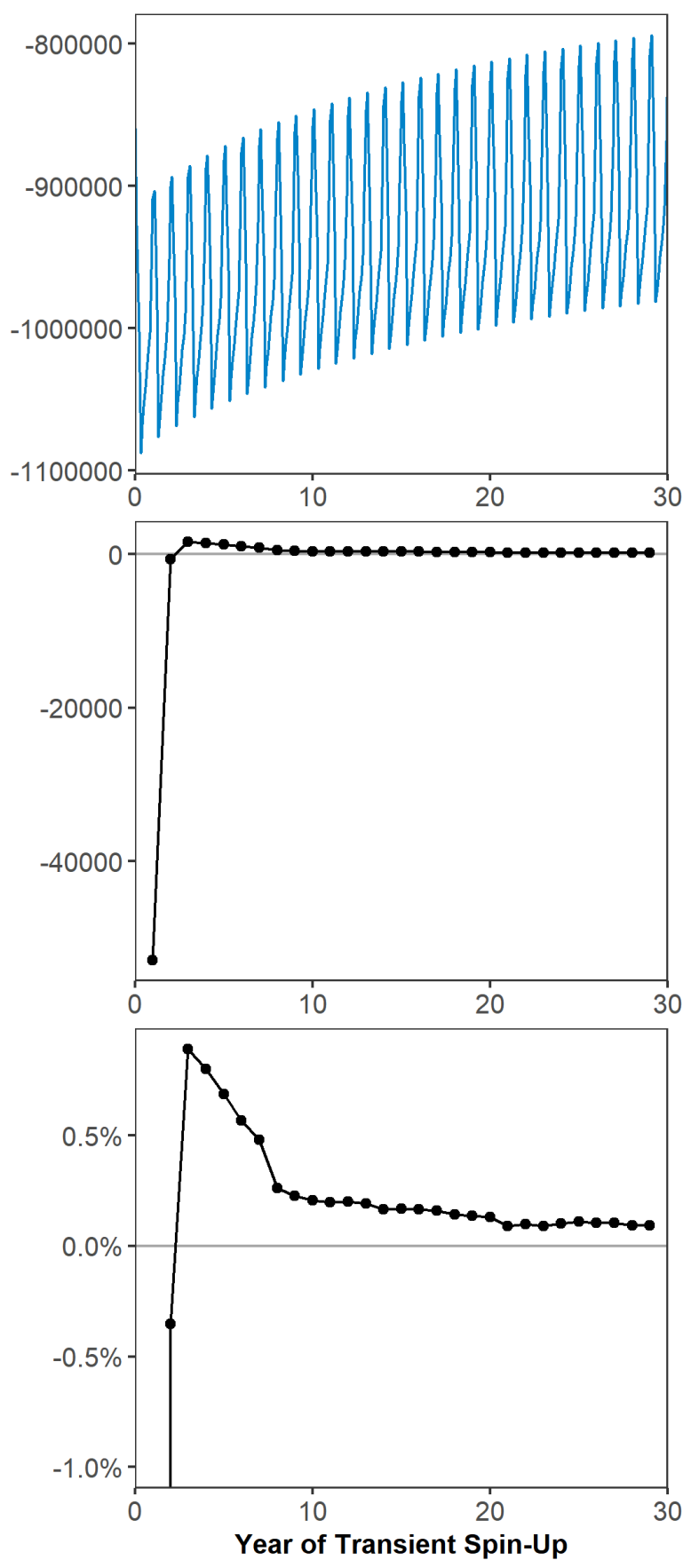

Figure S4. MODFLOW spin-up with stream features represented using RIV package (left column) and SFR2 package (right column). 
(a) MODFLOW

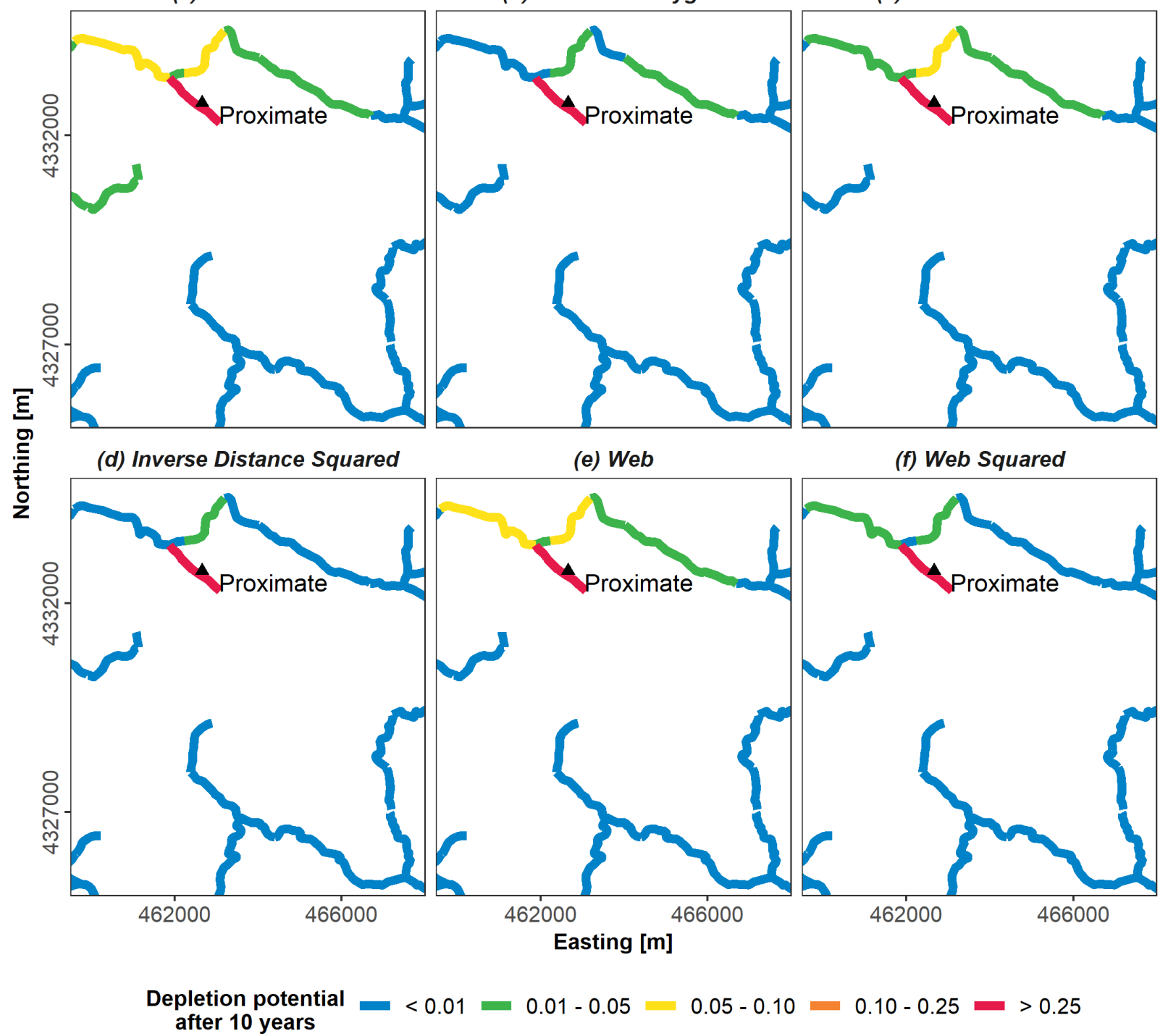

Figure S5. Example of the predicted distribution of depletion from the 'Proximate' well (see Figure S7) after 10 years of pumping calculated by (a) MODFLOW and (b-f) each of the depletion apportionment equations, combined with the Hunt analytical model and adjacent + expanding stream proximity criteria. 
(a) MODFLOW

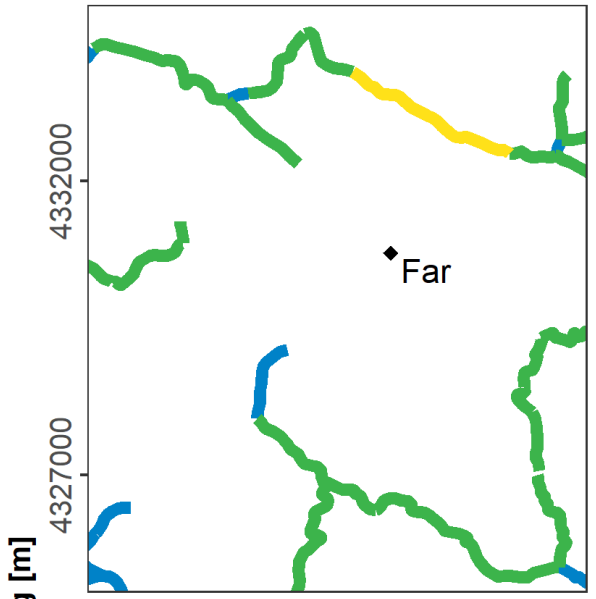

(d) Inverse Distance Squared

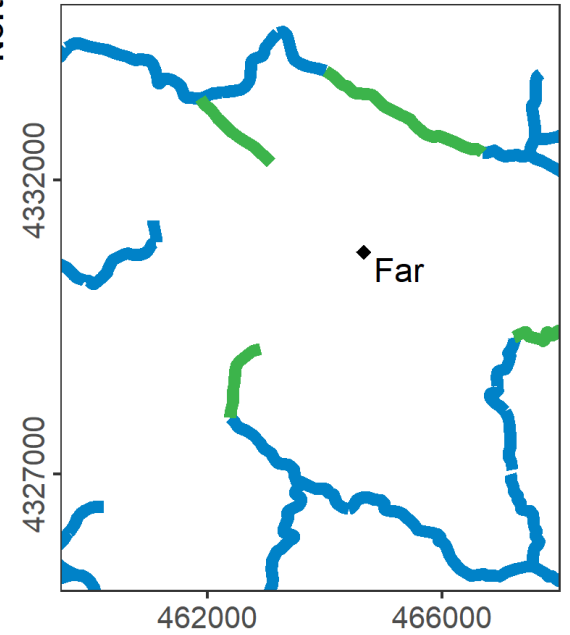

(b) Thiessen Polygon

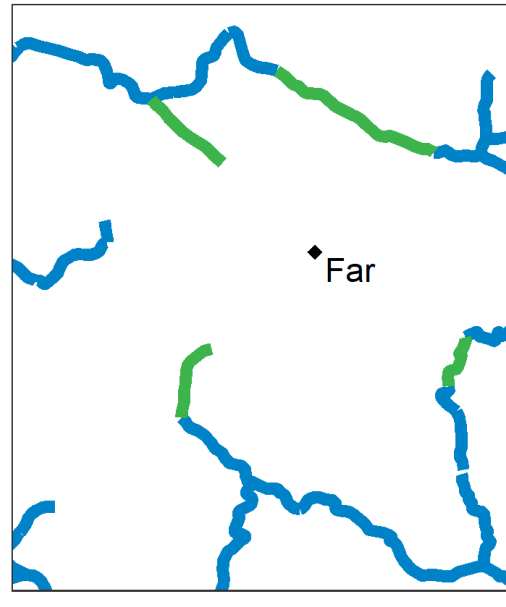

(e) Web

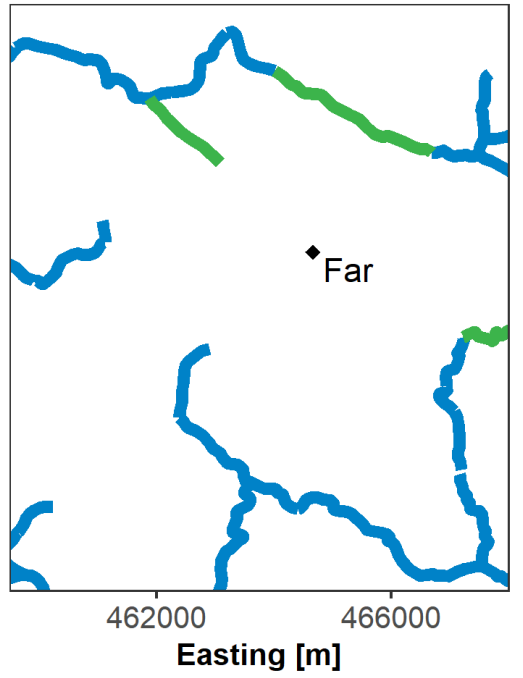

(c) Inverse Distance

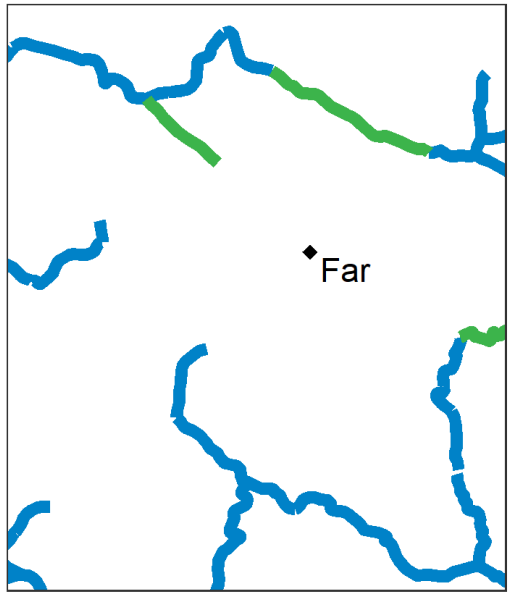

(f) Web Squared
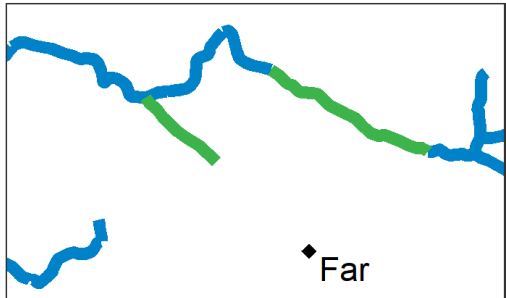

Far

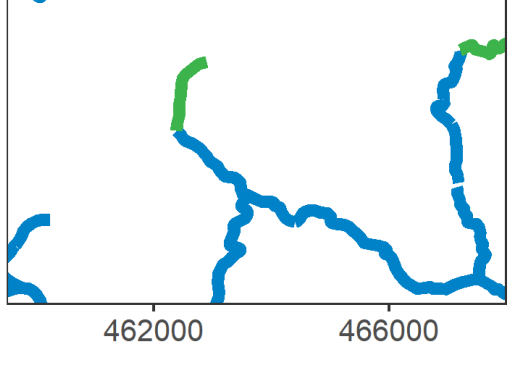

Depletion potential $\square<0.01 \square 0.01-0.05$
after 10 years

$0.05-0.10$

$0.10-0.25$

$>0.25$

Figure S6. Example of the predicted distribution of depletion from the 'Far' well (see Figure S7) after 10 years of pumping from (a) MODFLOW and (b-f) each of the depletion apportionment equations, combined with the Hunt analytical model and adjacent + expanding stream proximity criteria. 

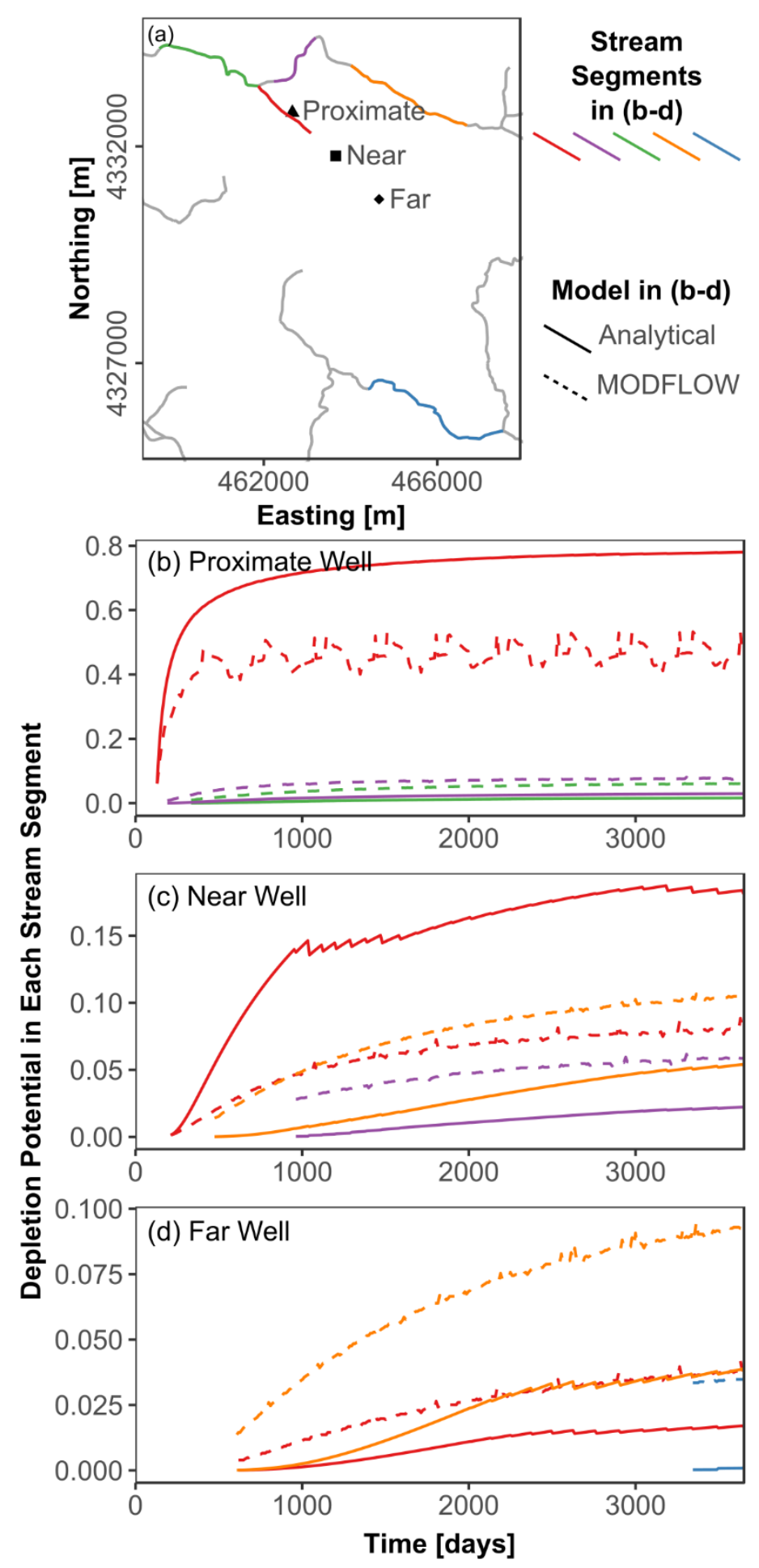

Figure S7. Comparison between transient MODFLOW with RIV stream features (dashed lines) and analytical (solid lines) for three example wells with varying distances to the closest stream segment. (a) Map of well locations (shapes) and stream segments. Depletion potential for 3 most-affected stream segments when pumping (b) proximate well, (c) near well, and (d) far well. Segment colors in (a) match lines in (b-d). Gray stream segments in (a) are not among the most affected stream segments for any of the three wells. Analytical results are for Hunt model, web squared depletion apportionment equation, and adjacent + expanding stream proximity criteria. 

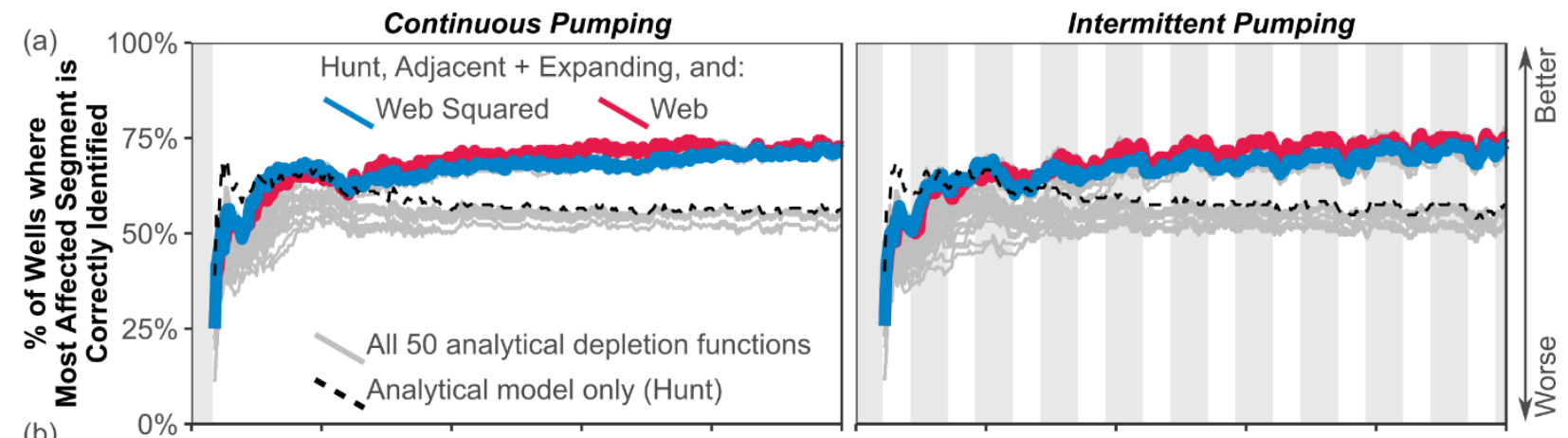

(b)
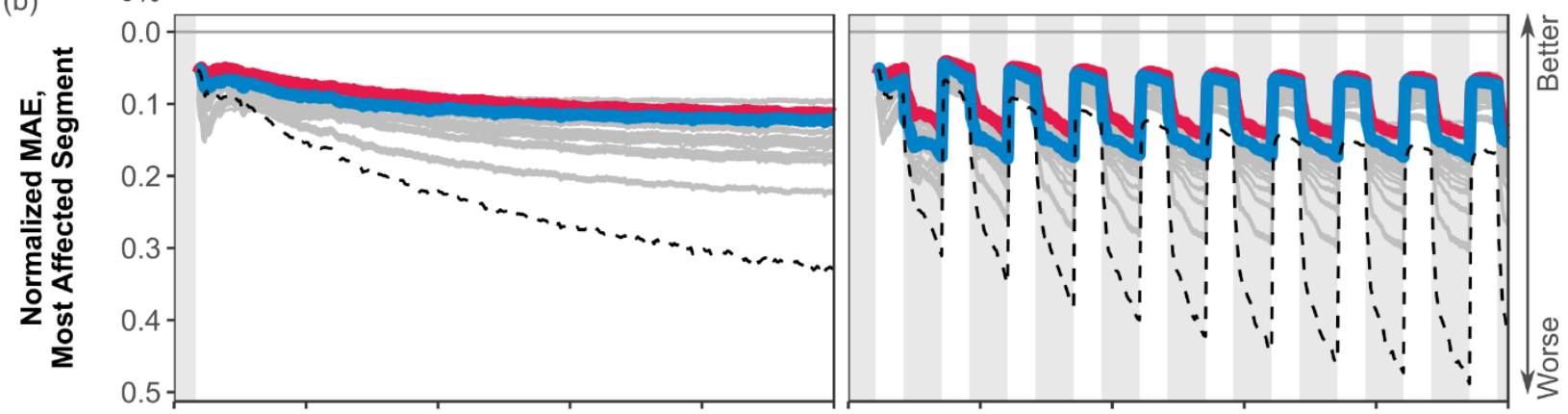

(c)
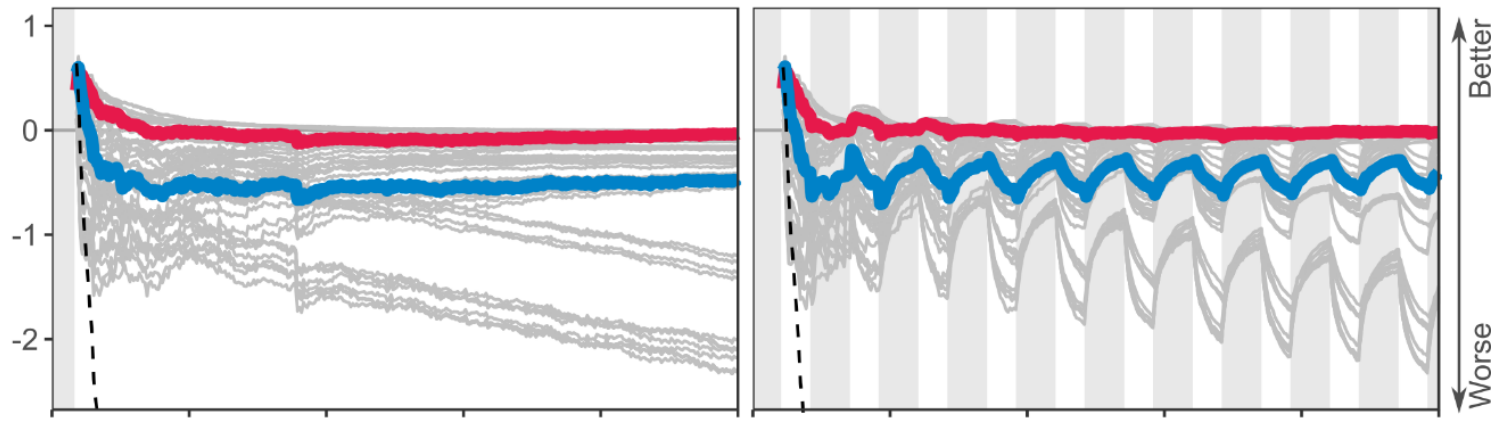

(d)
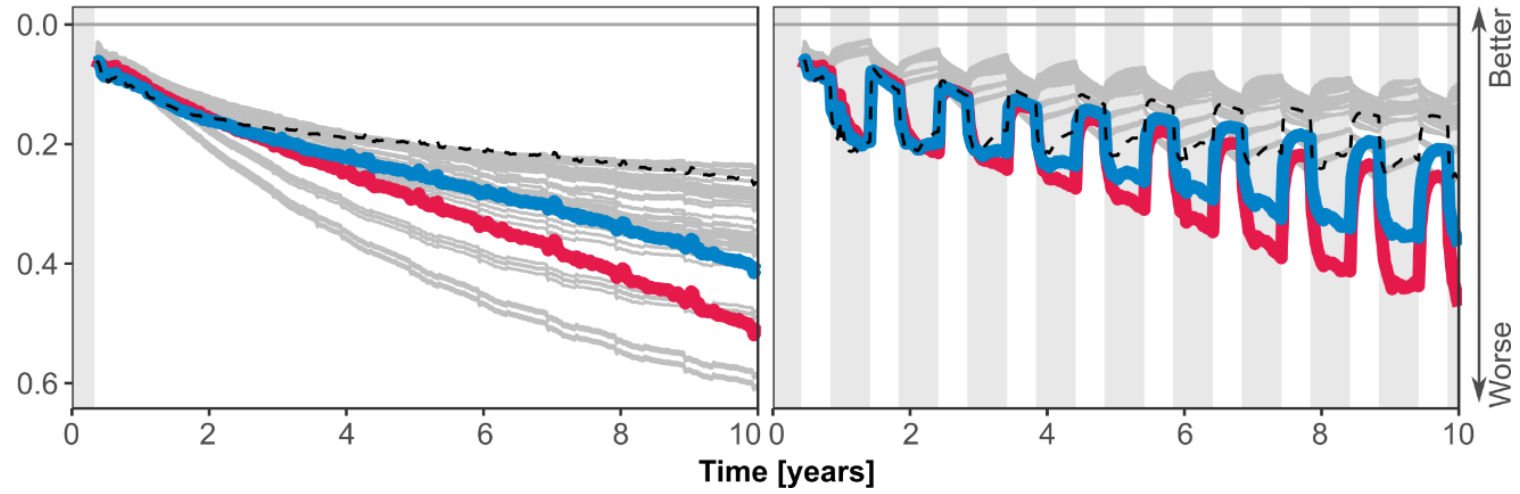

Figure S8. Comparison across all analytical depletion functions for each performance metric, evaluated using MODFLOW model with RIV package. (a) Spatial distribution of primary impact; (b) magnitude of primary impact; (c) spatial distribution of overall impacts; (d) magnitude of overall impacts. Note that yaxis is reversed on (b) and (d) so that upwards indicates better performance. Left column shows continuous pumping experiment and right column is intermittent pumping experiment. The gray lines show all 50 analytical depletion functions and the thick colored lines highlight the results from the Hunt model with adjacent + expanding stream proximity criteria and the web squared (blue) and web (red) depletion apportionment equations. The black dashed line shows the results for the Hunt analytical model alone (without the stream proximity criteria or depletion apportionment equations). 

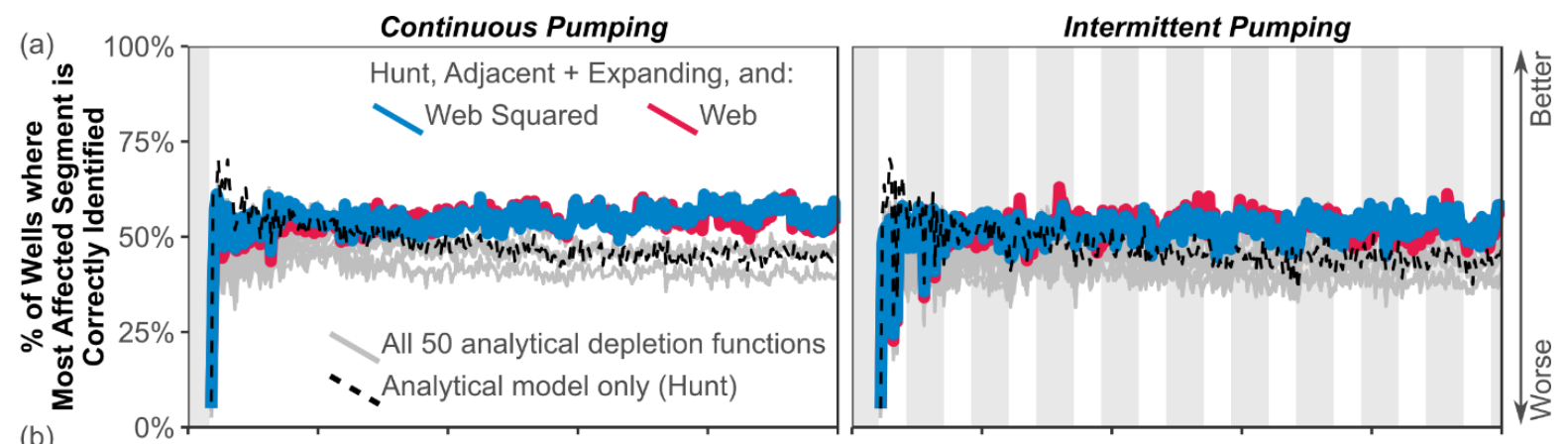

(b)
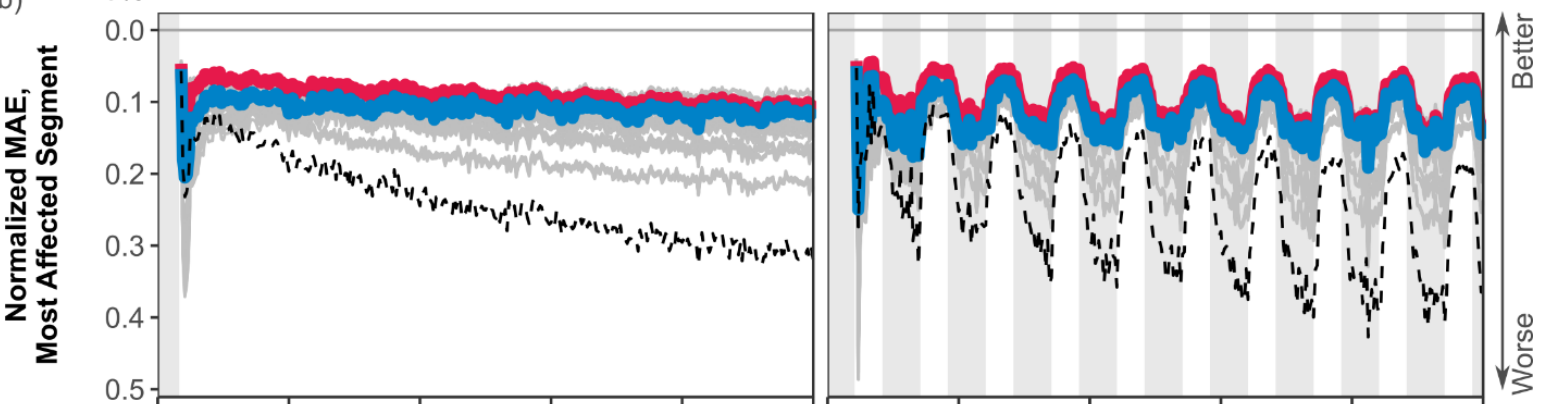

(c)
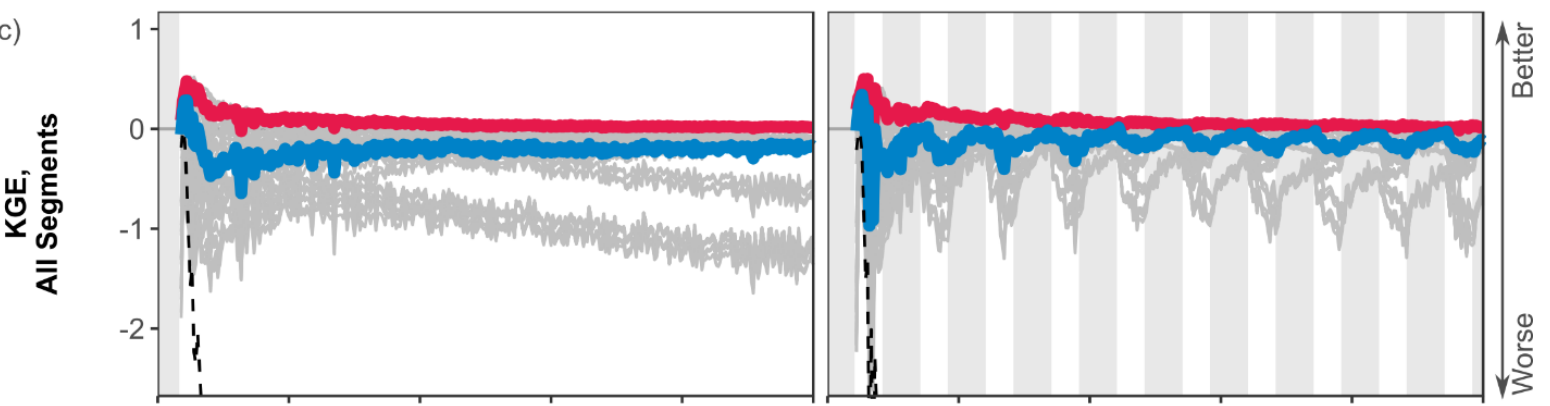

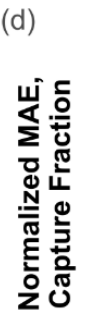
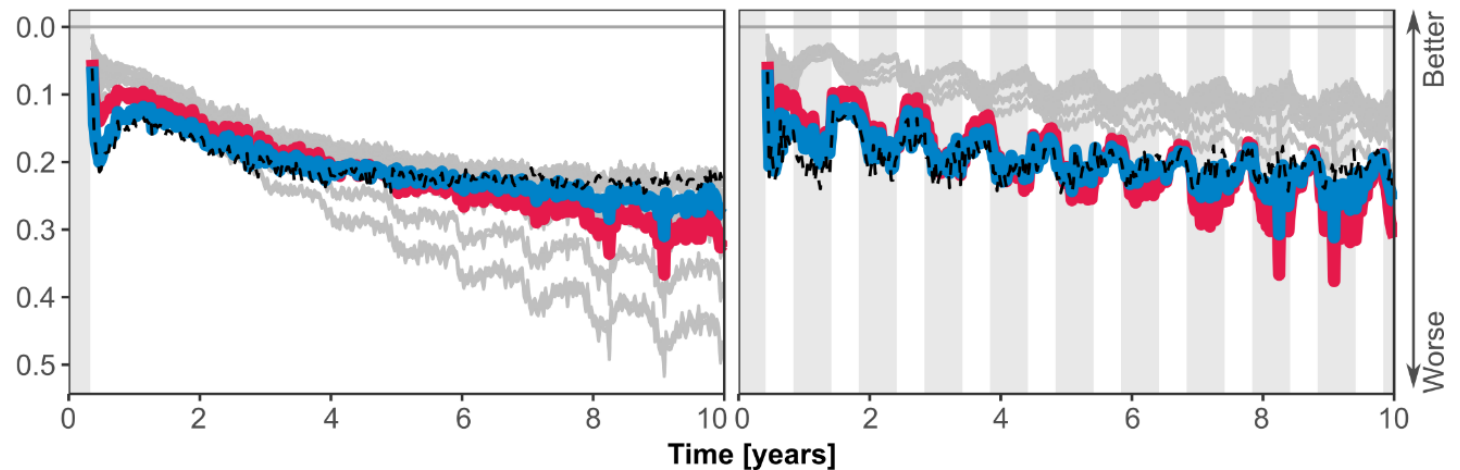

Figure S9. Comparison across all analytical depletion functions for each performance metric, evaluated using MODFLOW model with SFR2 package. (a) Spatial distribution of primary impact; (b) magnitude of primary impact; (c) spatial distribution of overall impacts; (d) magnitude of overall impacts. Note that $y$-axis is reversed on (b) and (d) so that upwards indicates better performance. Left column shows continuous pumping experiment and right column is intermittent pumping experiment. The gray lines show all 50 analytical depletion functions and the thick colored lines highlight the results from the Hunt model with adjacent + expanding stream proximity criteria and the web squared (blue) and web (red) depletion apportionment equations. The black dashed line shows the results for the Hunt analytical model alone (without the stream proximity criteria or depletion apportionment equations). 


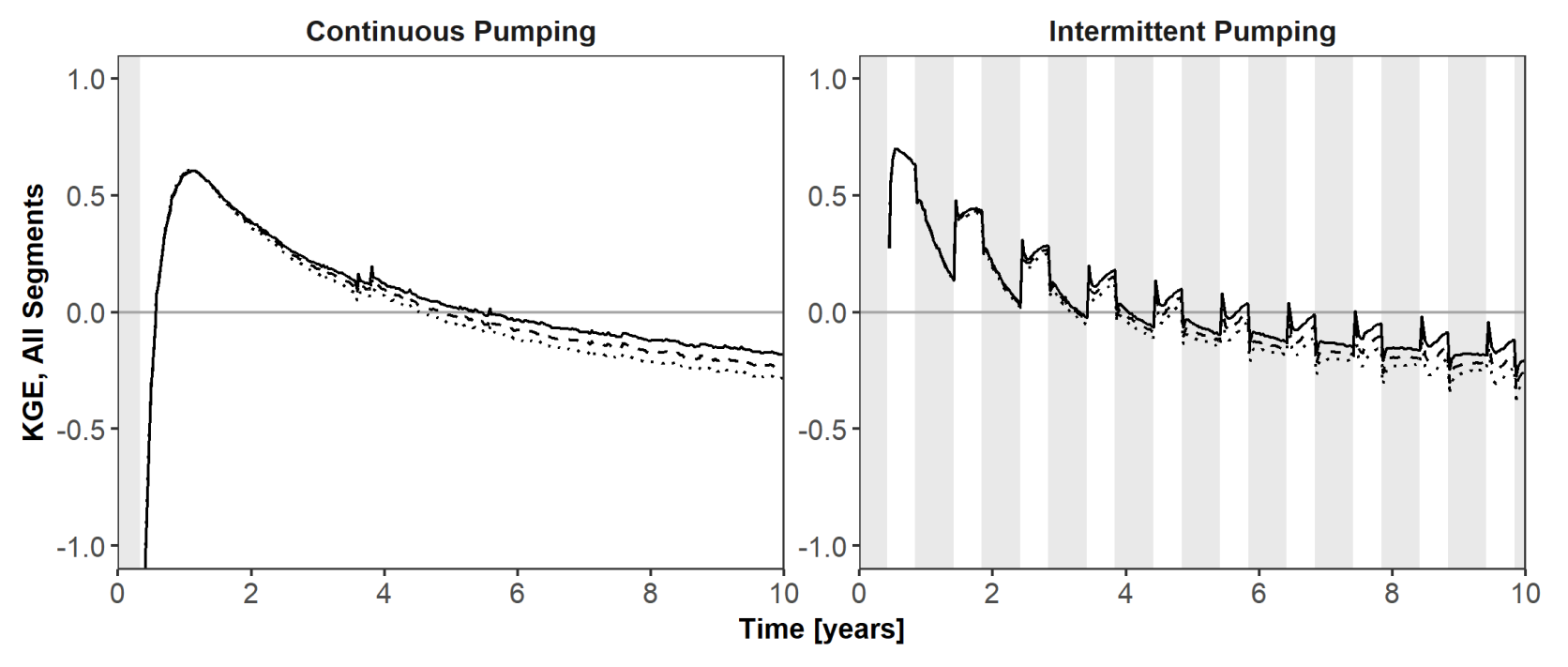

$$
\begin{aligned}
& \text { Adjacent + Expanding } \cdots \\
& \text { Percent Threshold }
\end{aligned}
$$

Figure S10. Comparison among different percent thresholds used to define adjacent + expanding stream proximity criteria. Plots show spatial distribution of overall impacts performance metrics for analytical depletion function using Hunt model and web squared depletion apportionment equation compared to MODFLOW model using RIV for stream features. 

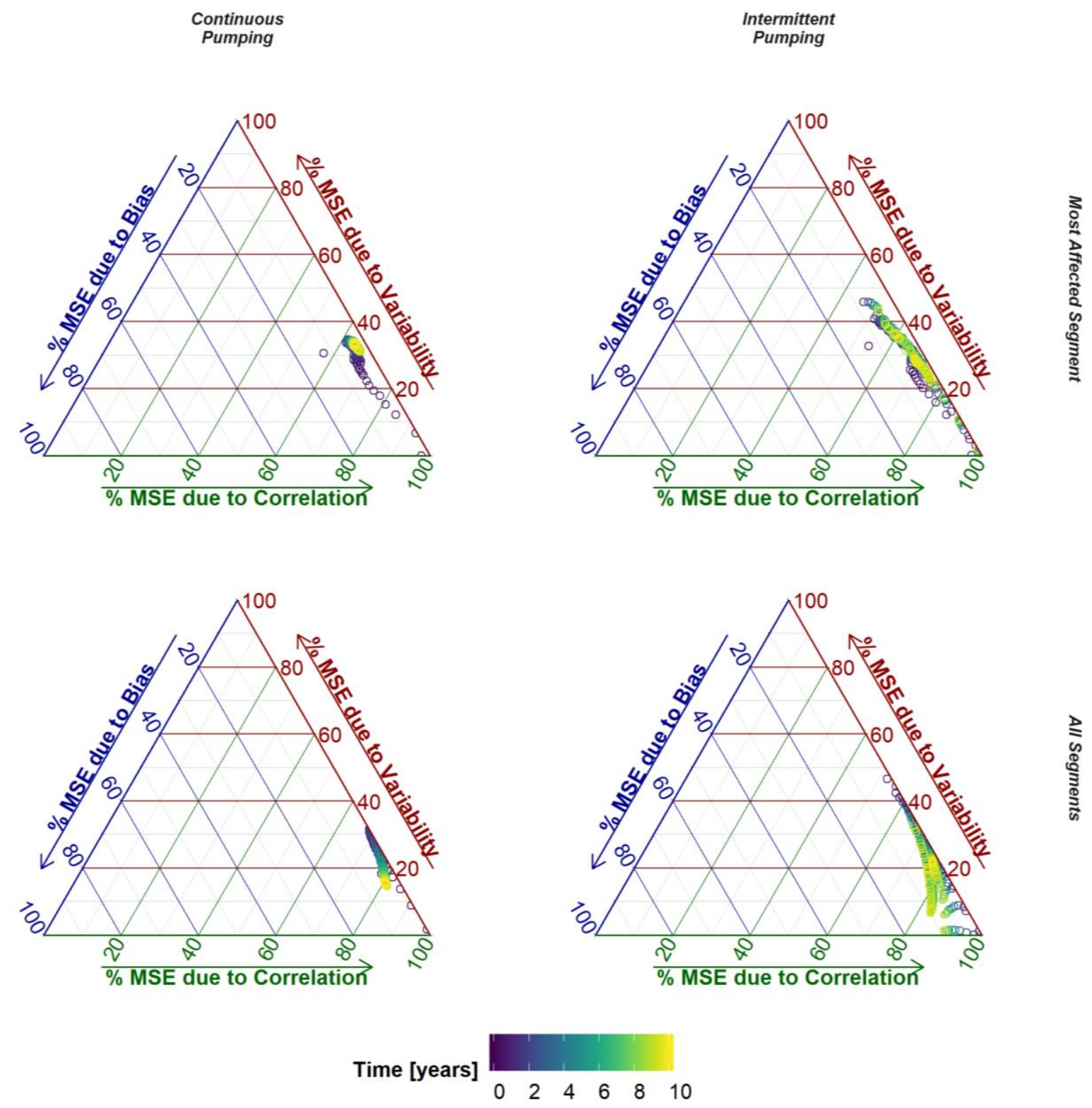

Figure S11. Relative contribution of variability, bias, and correlated to overall mean squared error (MSE) for the best-performing analytical depletion function compared to MODFLOW model using RIV for stream features. 
(a)

$\underset{\text { MAE }}{\text { Normalized }} \bigcirc 0.1 \bigcirc 0.2 \bigcirc 0.3 \bigcirc 0.4$
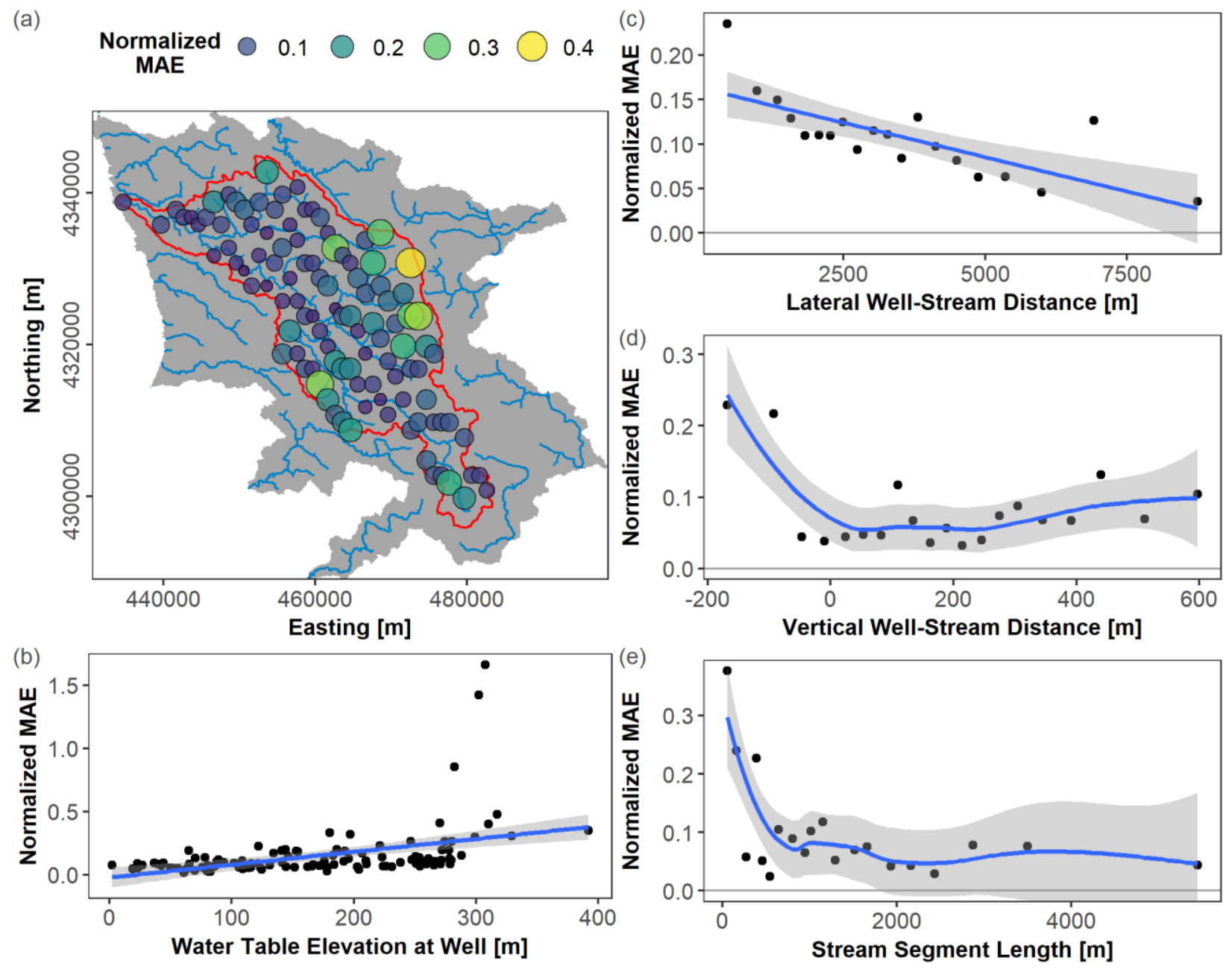

Figure S12 (as Figure 9, but for MODFLOW SFR model). Normalized MAE during the final year of the continuous pumping experiment for each well, shown by (a) position within domain, with the MODFLOW domain colored gray and streams colored blue; (b) steady-state water table elevation; (c) lateral distance between well and stream segment; (d) vertical distance between well and stream segment, where a negative value means the well is at a lower elevation than the stream; and (e) stream segment length. For each plot, the variable on the x-axis was divided into 20 quantiles used to calculate normalized MAE. Blue lines in (b) and (c) are linear best-fit $\left(R^{2}=0.29\right.$ and $R^{2}=0.72$, respectively; $p<10^{-5}$ for both), and blue lines in (d) and (e) are smoothed loess filters. MODFLOW model with SFR stream features used for evaluation. 


\section{References in SI}

Ahlfeld, D. P., Schneider, J. C., \& Spalding, C. P. (2016). Effects of nonlinear model response on allocation of streamflow depletion: exemplified by the case of Beaver Creek, USA. Hydrogeology Journal, 24(7), 1835-1845. https://doi.org/10.1007/s10040-016-1438-3

Feinstein, D. T., Fienen, M. N., Reeves, H. W., \& Langevin, C. D. (2016). A Semi-Structured MODFLOW-USG Model to Evaluate Local Water Sources to Wells for Decision Support. Groundwater, 54(4), 532-544. https://doi.org/10.1111/gwat.12389

Fienen, M. N., Bradbury, K. R., Kniffin, M., \& Barlow, P. M. (2018). Depletion Mapping and Constrained Optimization to Support Managing Groundwater Extraction. Groundwater, 56(1), 18-31. https://doi.org/10.1111/gwat.12536

Foglia, L., McNally, A., \& Harter, T. (2013). Coupling a spatiotemporally distributed soil water budget with stream-depletion functions to inform stakeholder-driven management of groundwater-dependent ecosystems. Water Resources Research, 49(11), 7292-7310. https://doi.org/10.1002/wrcr.20555

Jayawan, I. S., Demond, A. H., \& Ellis, B. R. (2016). Emerging investigators series: using an analytical solution approach to permit high volume groundwater withdrawals. Environmental Science: Water Research \& Technology, 2(6), 942-952. https://doi.org/10.1039/C6EW00108D

Kendy, E., \& Bredehoeft, J. D. (2006). Transient effects of groundwater pumping and surfacewater-irrigation returns on streamflow. Water Resources Research, 42(8), W08415. https://doi.org/10.1029/2005WR004792

Konikow, L. F., \& Leake, S. A. (2014). Depletion and Capture: Revisiting "The Source of Water Derived from Wells",,"' Groundwater, 52, 100-111. https://doi.org/10.1111/gwat.12204

Lackey, G., Neupauer, R. M., \& Pitlick, J. (2015). Effects of Streambed Conductance on Stream Depletion. Water, 7(1), 271-287. https://doi.org/10.3390/w7010271

Nathan, R. J., \& McMahon, T. A. (1990). Evaluation of automated techniques for base flow and recession analyses. Water Resources Research, 26(7), 1465-1473. https://doi.org/10.1029/WR026i007p01465

Reeves, H. W., Hamilton, D. A., Seelbach, P. W., \& Asher, A. J. (2009). Ground-waterwithdrawal component of the Michigan water-withdrawal screening tool (Scientific Investigations Report No. 2009-5003) (p. 36). Reston VA: U.S. Geological Survey. Retrieved from https://pubs.usgs.gov/sir/2009/5003/

Zipper, S. C., Dallemagne, T., Gleeson, T., Boerman, T. C., \& Hartmann, A. (2018). Groundwater pumping impacts on real stream networks: Testing the performance of simple management tools. Water Resources Research, 54(8), 5471-5486. https://doi.org/10.1029/2018WR022707 